\title{
Mechanisms of strength and stiffness improvement of paper after PFI refining with a focus on the effect of fines
}

\author{
Hamid Reza Motamedian • Armin E. Halilovic • Artem Kulachenko 1
}

Received: 9 November 2018/Accepted: 26 February 2019/Published online: 14 March 2019

(C) The Author(s) 2019

\begin{abstract}
Refining (i.e., mechanical beating of pulp) is a common procedure that is used in paper-making to improve the mechanical properties of the final product. The improvements caused by refining are mainly attributed to increased density and to a better bonding between fibers. In this work, we study how various mechanisms that can be triggered by refining affect the tensile behavior of the sheets. Consequently, we use direct numerical simulations of fiber networks. We relate our finding to the experimental measurements that we conducted on handsheets. We have found that fibrillar fines with size distributions below the resolution of modern state-of-the art pulp characterization tools have a substantial contribution to the increased strength and stiffness of the sheets.
\end{abstract}

Keywords Refining - Beating $\cdot$ PFI $\cdot$ Strength · Stiffness · Fines · Densification · Fiber network · Simulation

H. R. Motamedian - A. E. Halilovic · A. Kulachenko Department of Solid Mechanics, Royal Institute of Technology, 10044 Stockholm, Sweden

H. R. Motamedian · A. Kulachenko ( $\square)$

CD Laboratory for Fiber Swelling and Paper Performance,

Graz University of Technology, Inffeldgasse 23,

8010 Graz, Austria

e-mail: artem@kth.se

\section{Introduction}

Refining, or beating, is a mechanical treatment of pulp fibers to improve the properties of the final product. The effect of refining is attributed to the change of the mechanical and geometrical properties of the fibers and the fiber bonds. Through the effects introduced to the fibers, refining influences the density, porosity, formation and a number of other essential paper properties. The density of the sheet can affect the extent of modification in the elastic modulus and strength caused by refining. In a sparse sheet, the relative effect of refining is much bigger than in a high-density sheet, as the impact of bond parameters can be more significant (Brandberg and Kulachenko 2017). The main direct effects of refining on fibers, as presented in the literature, are as follows:

Internal fibrillation

Internal fibrillation is the delamination of the P and $\mathrm{S} 1$ layers of the fiber wall. Internal fibrillation is believed to be among the main reasons for the improvement of the strength properties of a paper network (Abitz and Luner 1989; Giertz 1957; Hartman 1985; Ingmanson and Thode 1959). As a result of internal fibrillation, the fibers will have a greater swelling potential because water can penetrate into the fibers' wall following the new voids that have been introduced by the mechanical action of refining. This increase in the 
swelling makes the fibers more compliant in the transverse direction, which results in better fiber conformability during sheet forming and is one reason behind sheet densification upon beating (Genco 1999). In addition, refining causes an increase in flexibility or, equivalently, a reduction of the bending stiffness. This is linked either to local damage in the fiber wall, such as delamination (Rusu et al. 2011), or to the reduction of the transverse shear and longitudinal stiffness of the fibers (Lammi and Heikkurinen 1997). Considering that hemicellulose, which acts as a glue to bond fibers together, is more available on the fiber surfaces due to the refining process (Gallay 1957; Giertz 1957), the increased conformability and flexibility lead to greater opportunities for bonding, larger bonded areas and stronger bonds between the fibers.

\section{External fibrillation}

External fibrillation is a phenomenon in which fibrils are pilled off from the fiber's surface (while they are still attached to the fiber). A number of researchers have concluded that external fibrillation enhances the bonding between fibers through mechanisms such as mechanical interlocking and, as a result, leads to paper with a higher tensile strength (Abitz and Luner 1989; Afra et al. 2013; Biermann 1996; Clark 1969; Jayme and Hunger 1957; Nanko and Ohsawa 1989; Page and Sargent 1957; Strachan 1932). However, there is evidence that external fibrillation has a negative effect on the tensile strength of paper, which is linked to a reduction of the fiber strength (Gallay 1957; Tasman 1969) and a weakening of the inter-fiber bonds (Cottrall 1950; Gallay 1949).

\section{Formation of fines}

The refining process causes the formation of small, detached fiber pieces, which are generally known as fines. Fines are formally defined as particles that pass through a $74-76 \mu \mathrm{m}$-diameter round hole or, nominally, a 200-mesh screen (ISO 10376:2011, n.d.; Seth 2003; TAPPI T $261 \mathrm{~cm}-94$, n.d.). Fines include detached segments of fibers, fibrils, lamellae fragments, ray cells, and do on. Fines are categorized into two groups based on their shape. In the first group are flake-like or chunky particles which are known as flour stuff (Brecht and Klemm 1953), flakes (Luukko 1998), and chunks (Forgacs 1963). These fines are described as being lignin-rich, with a small length to width ratio and a low potential to bond (Alince et al. 2001). They are known to have an adverse effect on the mechanical properties of the paper because they hinder the formation of fiber bonds. The second group of fines includes finer, flexible, and swellable cellulose-rich particles which are known as slime stuff (Brecht and Klemm 1953), fibrils (Luukko 1998), or ribbons (Forgacs 1963). This group of fines have a large length to width ratio and good bonding properties (Alince et al. 2001). They are known to contribute to the increased strength of paper.

In the case of the bleached chemical pulps, yet another classification of fines exists. The fines that are already present in the pulp before refining are called primary fines and those created during refining are called secondary fines. Secondary fines are mainly composed of fibrils (Retulainen et al. 1993) and they improve the strength of paper. External fibrillation and the formation of secondary fines during refining are naturally related (Kang 2007; Retulainen et al. 1993). However, the formation of fines is considered to have a greater impact on the strength of paper compared to external fibrillation (Hartman 1985; Kibblewhite 1975; Paavilainen 1990; Retulainen et al. 1993). This can be explained by the mobility of the fines and by the possibility to have a higher concentration at fiber crossings. This can increase the effective contact area of the bonded fibers and it can help to establish contact between close fibers, which would not be bonded in the absence of fines (Hartman 1985).

Two mechanisms have been suggested for the effect of fines on the strength of paper, namely: improving bonding between fibers and forming the load-carrying bridges between the fibers. The reasons behind the improved bonding have been discussed in various contexts. For example, fines have small sizes, and good swelling and chemical compatibility, and thus can fill the gap or openings between fibers at the bond locations (Retulainen et al. 1993). In contrast, evidence of the formation of bridges between fiber surfaces around the points of fiber crossings have been observed trough SEM and other imaging techniques (Alince et al. 2001; Buchanan and Lindsay 1957; Jayme and Hunger 1957; Page and Sargent 1957). Fines are speculated to reduce the stress concentrations in the bonded regions, which leads to more uniform stress distributions (Lobben 1978). 
It has also been demonstrated that the incremental addition of fibrillar fines to the same unrefined pulp leads to incrementally increased strength (Luukko and Paulapuro 1999; Retulainen et al. 1993). Similar results have been achieved through adding microfibrillated or nanofibrillated cellulose (Boufi et al. 2016).

Shortening of fibers through cutting

Another effect of refining is the shortening of fibers through cutting. This effect is generally considered to be negative for the tensile strength of paper (Nordström 2016). However, because the shortening of the fibers leads to a better formation (Bither and Waterhouse 1992), it has sometimes been found to have a positive effect on the strength of paper (Abitz and Luner 1989), in particular in paper with longer fibers (Biermann 1996).

Straightening or curling of fibers

Refining can cause both an increase (Nordström 2016) and a decrease in the fiber curl (Page 1989; Robertsén and Joutsimo 2004), depending on the pulp type and the refining equipment. Curl is known to have a direct coupling to tensile properties, particularly to stiffness. In addition, refining can cause straightening of fibers and removal of kinks (initial localized defects), which improves the stress distribution and results in higher strength (Dasgupta 1994). Some studies have also suggested that refining can improve fiber strength and stiffness by modifying the fibrillar angle, in addition to the removal of cell-wall defects (Alexander et al. 1968; Bither and Waterhouse 1992; Kim et al. 1975).

Combined effects on the sheet level

Refining pulp generally leads to a denser paper, which has higher stiffness and tensile strength. Although the main effects are usually attributed to improved bonding and densification, the contribution and exact mechanisms of each of the many factors listed earlier is still debated due to the overwhelming complexity of the phenomenon. For example, the role of fines and the exact mechanism through which they influence the properties is unclear. It is impossible to generalize the experimental findings since they are subjected to additional factors related to the choice of pulp (Gharehkhani et al. 2015; Rusu et al. 2011), refining method (Kerekes 2005; Stoere et al. 2001), degree of refinement (Joutsimo and Robertsé 2004), reference density of the product (Giertz 1957) and, finally, the mutual relations between these factors.

Traditionally, the bond strength has been studied using predominantly chemical pulp, while it is important to recognize the differences between the factors affecting the bonding propensity for the mechanical and chemical pulps. These factors include (Retulainen and Nieminen 1996; Vainio and Paulapuro 2007):

- the higher swelling/deswelling rate of chemical pulp fibers due to differences in acidic groups.

- the greater negative surface charge on the TMP fibers, which explains a limiting response to the addition of cationic strength additives.

- a greater degree of fibrillation of the TMP fibers, which makes the interlocking mechanism more influential and yet limits the effect of added fines, since the effect from the fibrillar content is already saturated.

In the present paper, we combine experimental and numerical methods to help us to understand the effect of PFI refining on chemi-thermomechanical pulp (CTMP). In particular, we focus on the effect of fines generated during refining and characterized using the state-of-the-art methods to assess the effect of refining on fine generation. The PFI mill is the most commonly used refining mill in lab-scale experiments (Kerekes 2005). This device consists of a stainless steel roll with bars and a smooth beater housing, which rotates at different speeds. The refining level is usually reported in revolutions or alternatively in PFI count which is equal to 10 revolutions. CTMP is made of wood chips that are pretreated with chemicals before undergoing a thermo-mechanical process. The chemical treatment of CTMP is less vigorous than in a chemical pulping process as the goal is to prepare the fibers for mechanical treatment and not to remove the lignin. From the morphological point of view, CTMP pulp consist of bulky, often uncollapsed fibers of medium or large length-to-width ratio. This pulp is widely used in the medium ply of the commercial paper boards. 


\section{Experiments and measurements}

The material used for this study was chemi-thermomechanical pulp (CTMP), which was made from spruce and is often found in the middle layer of commercial paper boards. The CTMP pulping process is a hybrid between chemical and mechanical pulping in that the wood is treated with chemicals before mechanical treatment. However, in contrast to chemical pulping, the lignin that gives the fibers their plastic behavior is preserved in CTMP. The main chemical added to the pulp is sodium sulfate, which is added to the wooden chips before the refining process.

In this study, we have tested six different materials with various combinations of refining and strength additives; that is, three different refining levels, each with and without strength additives. The material was provided by StoraEnso, Karlstad, Sweden. The strength additive that we used in the material for this article was Avebe Amlofax HS, which is a potato based cationic starch with DS $0.045-0.049 \mathrm{~mol} / \mathrm{mol}$ degree of substitution. This strength additive was added to half of the samples at $25 \mathrm{~kg} / \mathrm{t}$. The pulp was mechanically beaten between two rotating cylinders in a PFI mill. An increased number of PFI mill revolutions corresponds to a more refined pulp. The three different levels of refining were 0, 1000, and $2000 \mathrm{PFI}$ mill revolutions. Here, 0 PFI mill revolutions refer to the unbeaten pulp. Different combinations of strength additive and refining level, including the naming convention that will be used in the rest of this article are shown in Table 1.

Table 1 Different combinations of strength additives and refining levels

\begin{tabular}{lcc}
\hline Material & Strength additive $(\mathrm{kg} / \mathrm{t})$ & Refining (PFI revolutions) \\
\hline R0 & 0 & 0 \\
R1000 & 0 & 1000 \\
R2000 & 0 & 2000 \\
SR0 & 25 & 0 \\
SR1000 & 25 & 1000 \\
SR2000 & 25 & 2000 \\
\hline
\end{tabular}

Pulp characterization

The pulps were characterized to find the geometrical data of the fibers and fines in the pulps with different degrees of refining. Pulp characterization is the measuring of the dimensions of the fibers in a pulp. These measured dimensions are shown schematically in Fig. 1. These characterization data were used not only to investigate the effect of refining but also in the numerical modeling of the networks, as described in "External fibrillation" section. We used two different devices for characterization: a Kajaani (presently Valmet) Fiber Image Analyzer Analyzer at PTS (Papiertechnische Stiftung), Munich, Germany and an L\&W Pulp Tester Plus at Graz University, Graz, Austria. The main difference between the devices is that the L\&W Pulp Tester Plus has a better resolution and can detect and characterize more fines and smaller fibers while Kajaani can report extra parameters such as fiber wall-thickness and number of kinks. The resolution and measurement limitations of the characterization devices is given in Table 2. In the data from Kajaani Fiber Image Analyzer, for all the particles with lengths lower than $200 \mu \mathrm{m}$, which are categorized as fines, no other data apart from the length is reported. For the sake of consistency, we use the same length criteria to differentiate between fibers and fines in the rest of this article. In other words, all the fibers with length lower than $200 \mu \mathrm{m}$ will be considered fines, although it is not strictly according to the standard definition of fines which was mentioned previously in Sect. 1.

The distributions of the measured parameters including fiber length, width, wall-thickness, shape factor, external fibrillation, kinks, and fine length, width, and aspect ratio using both characterization devices (if data was available) are shown in Figs. 23, 24, 25, 26, 27, 28, 29, 30 and 31 of "Appendix". The arithmetic, as well as the length-weighted averages for these distributions, are gathered in Table 3 for data from the Kajaani Fiber Image Analyzer and in Table 4 for data from the L\&W Pulp Tester Plus. These averages are calculated according to the following equations:

Arithmetic average of $\mathrm{P}=\frac{\sum_{i=1}^{n} P_{i}}{n}$ 


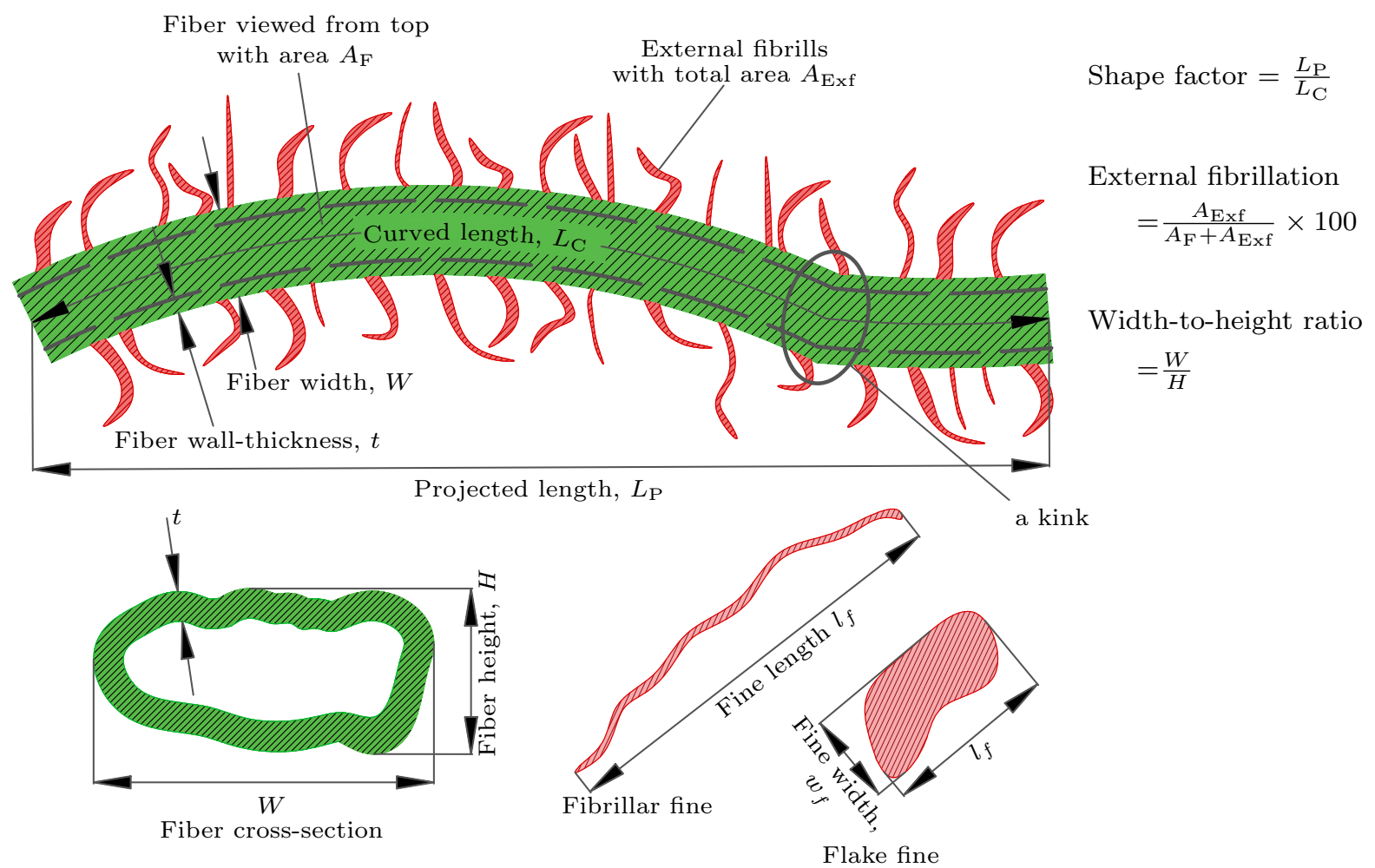

Fig. 1 Schematic visualization of measured fiber and fine dimensions

Table 2 Resolution and measurement limitations of the characterization devices

\begin{tabular}{|c|c|c|c|c|}
\hline \multirow[t]{2}{*}{ Device name } & \multicolumn{2}{|c|}{ Length measurement } & \multicolumn{2}{|c|}{ Width measurement } \\
\hline & Minimum $(\mu \mathrm{m})$ & Resolution $(\mu \mathrm{m})$ & Minimum $(\mu \mathrm{m})$ & Resolution $(\mu \mathrm{m})$ \\
\hline Kajaani & 10 & 10 & $1\left(2.5^{*}\right)$ & 1.5 \\
\hline L\&W Pulp Tester & $4(7 *)$ & 0.1 & $4(7 *)$ & 0.1 \\
\hline
\end{tabular}

*Values in parenthesis are based on measured data while the others are according to device data sheets

Table 3 Mean values of pulp characterization data from Kajaani

\begin{tabular}{|c|c|c|c|c|c|c|}
\hline \multirow{2}{*}{$\begin{array}{l}\text { Averaging method } \\
\text { Pulp }\end{array}$} & \multicolumn{3}{|c|}{ Arithmetic } & \multicolumn{3}{|c|}{ Length-weighted } \\
\hline & R0 & R1000 & R2000 & R0 & R1000 & R2000 \\
\hline Fiber length (mm) & 0.966 & 0.925 & 0.917 & 1.694 & 1.614 & 1.591 \\
\hline Fiber width $(\mu \mathrm{m})$ & 30.2 & 29.4 & 29.7 & 36.1 & 35.3 & 34.8 \\
\hline Fiber wall-thickness $(\mu \mathrm{m})$ & 8.9 & 8.5 & 8.1 & 11.1 & 10.4 & 9.9 \\
\hline Fiber shape factor $(-)$ & 0.91 & 0.91 & 0.91 & 0.91 & 0.91 & 0.92 \\
\hline External fibrillation (\%) & 4.33 & 4.92 & 4.46 & 3.83 & 4.43 & 4.36 \\
\hline Fine length $(\mu \mathrm{m})$ & 117.9 & 119.8 & 117.6 & 140.8 & 142.1 & 142.0 \\
\hline
\end{tabular}


Table 4 Mean values of pulp characterization data from L\&W Pulp Tester Plus

\begin{tabular}{lccccccc}
\hline Averaging method & \multicolumn{3}{l}{ Arithmetic } & & & \multicolumn{2}{l}{ Length-weighted } \\
\cline { 2 - 3 } \cline { 7 - 8 } Pulp & R0 & R1000 & R2000 & & R0 & R1000 & R2000 \\
\hline Fiber length $(\mathrm{mm})$ & 0.744 & 0.698 & 0.659 & & 1.555 & 1.370 & 1.297 \\
Fiber width $(\mu \mathrm{m})$ & 30.2 & 30.7 & 30.2 & & 36.9 & 36.8 & 36.3 \\
Fiber shape factor $(-)$ & 0.86 & 0.87 & 0.87 & & 0.85 & 0.86 & 0.86 \\
Fine length $(\mu \mathrm{m})$ & 25.7 & 25.5 & 25.5 & & 51.4 & 50.8 & 50.1 \\
Fine width $(\mu \mathrm{m})$ & 16.5 & 16.4 & 16.5 & & 20.0 & 19.8 & 19.9 \\
Fine aspect ratio $(-)$ & 1.5 & 1.5 & 1.5 & & 2.8 & 2.8 & 2.8 \\
\hline
\end{tabular}

Length-weighted average of $P=\frac{\sum_{i=1}^{n}\left(P_{i} \times L_{i}\right)}{\sum_{i=1}^{n} L_{i}}$

where $P$ is the parameter to be averaged, $n$ is the total number of fibers/fines, and $L_{i}$ is the length of $i$ th fiber/ fine. It is seen that although the refining has slightly reduced the average length of the fibers, the other geometrical properties of the fibers and fines are not affected considerably. Specifically, no considerable change in width and wall-thickness of fibers was detected. It is known that the main effect of internal fibrillation is an increase in the wall-thickness due to intensified swelling. The characterization results indicate that the internal fibrillation, which might be the dominant effect of refining in some cases, is not a major factor in this specific case.

We know that although the PFI mill is considered to cause less external fibrillation in comparison with other refining devices (Stoere et al. 2001), it proves to be very effective in creating fines (Kibblewhite 1972). The distribution of fine aspect ratios is shown in Fig. 31 and the mean values of fine aspect ratios are given in Table 4. These data show that the fines captured by the L\&W Pulp Tester Plus are mostly flake fines and are not fibrillar fines. The secondary fines (i.e., fines created by refining) are mostly fibrillar fines that have a width in the range $250-350 \mathrm{~nm}$ (Sundberg and Holmbom 2004; Sundberg et al. 2003) and which cannot be detected by the characterization devices. The non-fibrillar fine content of the pulps calculated using the data from the L\&W Pulp Tester Plus is shown in Table 5. These data show that refining has resulted in the formation of flake fines as well. These fines are mostly broken parts of fibers or fiber walls. This is consistent with the results on the length of fibers, which showed a slight shortening.
Table 5 Fine content using data from L\&W Pulp Tester Plus

\begin{tabular}{llllll}
\hline Pulp & \multicolumn{2}{l}{ All fines } & & \multicolumn{2}{l}{ Fines with aspect ratio $>4$} \\
\cline { 2 - 3 } \cline { 5 - 6 } & Arithmetic & Volumetric & & Arithmetic & Volumetric \\
\hline R0 & 97.6 & 22.6 & 2.4 & 0.9 \\
R1000 & 97.7 & 24.2 & 2.4 & 1.0 \\
R2000 & 97.8 & 27.0 & 2.4 & 1.1 \\
\hline
\end{tabular}

Another finding from the characterization data, as shown in Fig. 28 in "Appendix" is that the percentage of kinked fibers in the pulp has not changed with refining. This can be interpreted as a sign that the properties of the fibers are not significantly affected by the refining process.

Dewatering tests

One way to compare the fibrillar fine content (and also the external fibrillation) of different pulps is to examine the dewatering property of the pulps. Dewatering is the measurement of the freeness of the pulp or the drainability of the pulp suspension. In other words, it is a measure of the rate at which a dilute suspension of pulp may be drained. In general, if network constituents (fibers, fines, etc.) can have larger swelling, they will take more water inside their structure and decrease the freeness of the pulp (Scallan 1983). However, we were not able to detect a significant difference between neither the widths nor the wall-thicknesses of the pre-swelled fibers with different levels of refining using the fiber characterization tools (see Figs. 24, 26). Another reason for increased dewatering time can be a higher fine content and external fibrillation, because fibrils and fibrillar fines have a high tendency to swell. 
The dewatering of our pulps is measured by two different methods. The first method is SR [SchopperRiegler (ISO 5267-1:1999, n.d.)] method, which is common for chemical pulps. A higher dewatering number in this method indicates slower draining. The second method that we used is the CSF [Canadian Standard Freeness (ISO 5267-2:2001, n.d.; TAPPI T 227 om-99, n.d.)] method, which is mostly used for mechanical pulps. In this method, higher numbers mean faster draining or a more easily dewatered pulp. The results are shown in Table 6. The data from both methods are consistent and they clearly show that there is a significant difference between the freeness levels and, thus, in the fibrillar fine content of our different pulps. However, this was not detected by the optical characterization tools due to limited resolution. We will investigate the effect of the existence of these fibrillar fines using numerical simulations, as described in "External fibrillation" section.

\section{Micro-tomography}

The fiber characterization that was data presented in the previous section was extracted from pulps containing saturated swollen fibers. However, given that the focus of the study is on the dry strength, the use of this data as an input in the subsequent network-level simulation tools is not viable. To relate the gathered data to the dry state, we engaged the micro-tomography equipment and analyzed staples of handsheets produced from pulps of different refining levels. These handsheets were later used in mechanical testing.

The machine that we employed to acquire the micro-tomography data was an Xradia MicroXCT200 at Innventia, Stockholm, Sweden. The sample size was $1.5 \mathrm{~mm}$ in diameter and the image element (voxel) size was $0.5 \mu \mathrm{m}$ along all three axes. Three different samples (R0, R1000, R2000) were studied. Due to the small size of the samples most of the fibers were cut

Table 6 Dewatering properties of pulps with different refining levels

\begin{tabular}{lll}
\hline Pulp & SR (mL) & CSF (mL) \\
\hline R0 & 20.8 & 590 \\
R1000 & 25.6 & 500 \\
R2000 & 30.8 & 410 \\
\hline
\end{tabular}

and the data regarding fiber length and as a result, shape factor could not be extracted reliably. We assume that during the handsheet making and subsequent constrained drying, the length and the shape of the fibers is not affected significantly, so that we can rely on the length and shape factor data acquired by the fiber characterization tools. To obtain the crosssectional dimensions, more than 100,000 cross-sections per sample were analyzed. Only those crosssections corresponding to free segments (not bonded to other fibers) were processed and the results were averaged over the identified fibers. The analysis method that we used is presented in (Wernersson et al. 2014). The distributions of measured parameters including fiber width, height, wall-thickness, and width-to-height ratio are processed, and the mean values and standard deviations for these parameters are given in Table 7. Due to internal fibrillation, the fibers become more collapsible. This can potentially affect the width-to-height ratio of the fibers in different samples. However, we found that width-to-height ratio of the fibers had no noticeable change after refining, which means that internal fibrillation is not a remarkable outcome of beating in our case. This result collaborates with our previous finding from pulp characterization data in the wet state, which did not show significant changes of the cross-section. The changes in the bonds could not be reliably processed due to uncertainties in identifying the individual fibers in the bond region.

Mechanical properties of the handsheets

For each combination of refining level and strength additive amount, 10 handsheets were prepared under identical conditions by StoraEnso, using Rapid Köthen sheet-making equipment according to ISO 5269-2:2004 standard. The diameter of all of the handsheets was $15.9 \mathrm{~cm}$. The thickness of the handsheets was measured using STFI Thickness Tester M201 and the weight was found using Sartorius BP110 S. Consequently, the grammage and density of handsheets were calculated by dividing the weight by the area, and the grammage by the thickness, respectively. The mean thickness, grammage, and density for all of the combinations are shown in Table 8 .

To study the effect of refining on the strength and stiffness of the samples, an Alwetron Th1 machine by Lorentzen\&Wettre was used. For each pulp, 10 test 
Table 7 Mean and standard deviation for cross-sectional dimensions from micro-tomography
Table 8 Mean values of thickness, grammage, and density for different samples

\begin{tabular}{lrrrrrrr}
\hline Pulp & \multicolumn{2}{l}{ Mean } & & & \multicolumn{3}{l}{ Standard deviation } \\
\cline { 2 - 3 } & R0 & R1000 & R2000 & & R0 & R1000 & R2000 \\
\hline Fiber width $(\mu \mathrm{m})$ & 25.54 & 25.95 & 25.69 & & 5.6 & 5.7 & 5.1 \\
Fiber height $(\mu \mathrm{m})$ & 14.85 & 15.05 & 15.25 & & 3.4 & 3.0 & 3.2 \\
Wall-thickness $(\mu \mathrm{m})$ & 3.09 & 4.00 & 3.23 & & 0.75 & 0.85 & 0.63 \\
Width-to-height ratio & 1.85 & 1.78 & 1.78 & & 0.85 & 0.44 & 0.62 \\
\hline
\end{tabular}

\begin{tabular}{llll}
\hline Pulp & Thickness $(\mu \mathrm{m})$ & Grammage $\left(\mathrm{g} / \mathrm{m}^{2}\right)$ & Density $\left(\mathrm{kg} / \mathrm{m}^{3}\right)$ \\
\hline R0 & 521.3 & 151.2 & 290.1 \\
R1000 & 443.7 & 153.2 & 345.2 \\
R2000 & 377.0 & 148.4 & 393.7 \\
SR0 & 547.4 & 156.1 & 285.1 \\
SR1000 & 423.3 & 153.6 & 362.7 \\
SR2000 & 349.1 & 144.5 & 414.0 \\
\hline
\end{tabular}

samples (60 test samples in total) with dimensions of $100 \mathrm{~mm} \times 15 \mathrm{~mm}$ were prepared and tested in in a climate controlled environment at a temperature of 23 ${ }^{\circ} \mathrm{C}$ and $50 \%$ relative humidity. The testing device measured forces and elongations, which were transformed into stress and strain using the dimensions of the samples. The mean stress-strain curves for handsheets produced from all the six different pulps are shown in Fig. 2. The combined effect of refining and strength additive on the strength and stiffness of paper

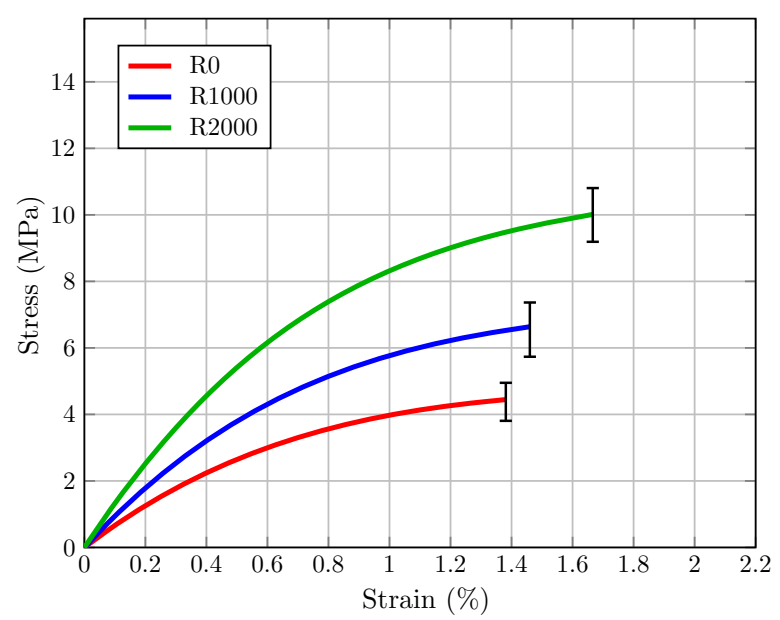

(a)

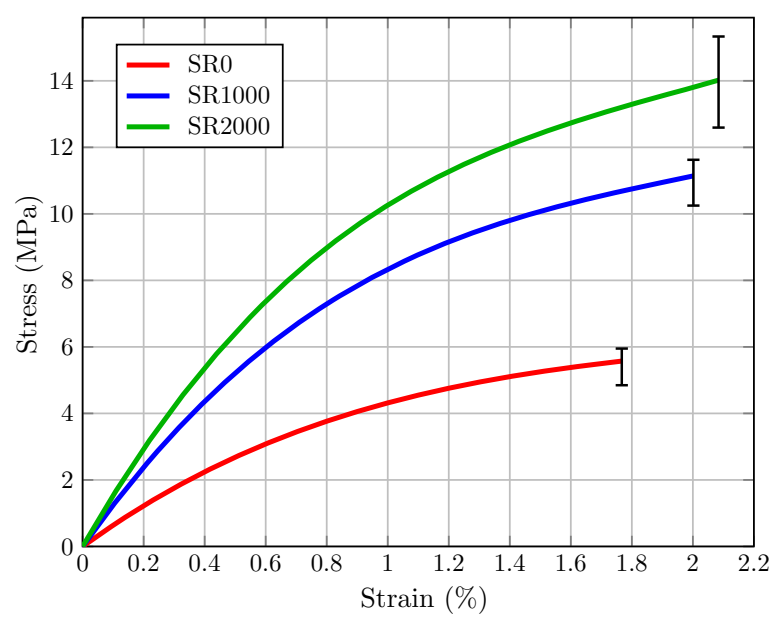

(b)

the strength results from testing 10 samples for each material and the curves represent the averages
Fig. 2 Stress-strain curves from the uniaxial tensile test, a refined pulp without strength additives and $\mathbf{b}$ refined pulp with strength additive. The bars show the maximum and minimum of is demonstrated in Fig. 3. We observe that the impact of refining on both strength and stiffness is intensified when strength additives are present. We also see that although the strength additives improve the strength of paper and stiffness of paper from refined pulps, they do not affect the stiffness of unbeaten paper. In other words, to increase the stiffness of paper, refining is necessary and increased bond strength alone cannot lead to stiffness improvements. 


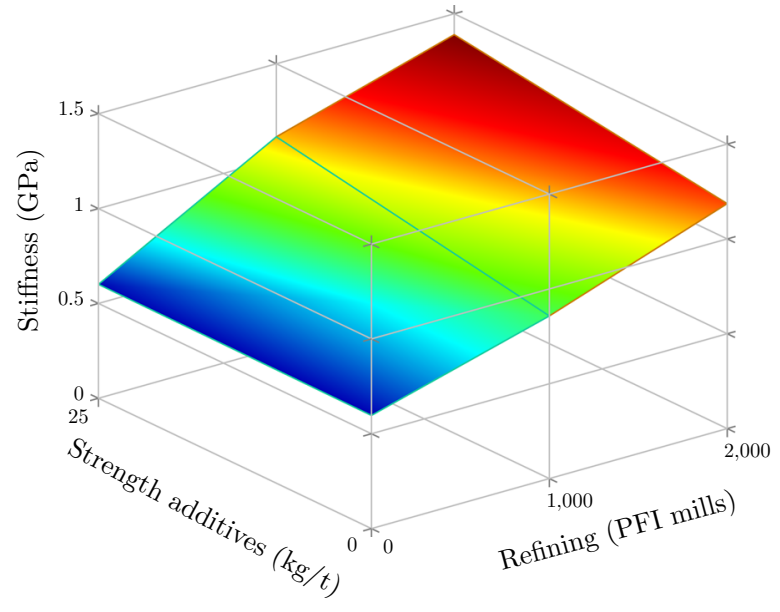

(a)

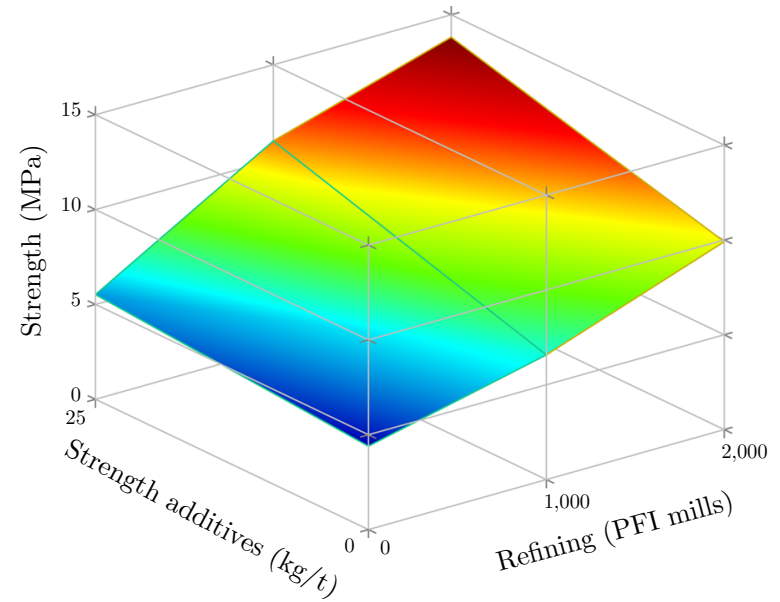

(b)

Fig. 3 Combined effect of refining and strength additive on a stiffness and $\mathbf{b}$ strength of paper

We observed the densification caused by refining at a constant level of wet-pressing. The wet-pressing is another tool which can cause densification. The elastic modulus of the sheets densified by wet-pressing scales linearly with density in a fashion similar to the one caused by refining. The effect on the strength is different, however. The sheets densified due to beating generally have greater strength at a given density. This effect is attributed to the increased bonding strength and it is also linked to the addition of fines. In fact, the addition of fines causes the densification and improved strength as well (Niskanen 2008). It is hard to distinguish the effects coming from the improved bonding and reinforcement by the fines experimentally.

\section{Retention of strength additives}

As refining can potentially change the retention of the strength additive (i.e., cationic starch), a test was conducted at MoRe Research Örnsköldsvik AB, Domsjö, Sweden to compare the mass percentage of starch present in the dry sheet. The test was conducted on SR0, SR1000, and SR2000. The results are shown in Table 9. As seen in this table, the difference between the retention of pulps with different levels of refining is not significant. This means that the amount of remaining starch in the handsheets from these pulps is approximately the same, and the interaction between refining and strength additives cannot be
Table 9 Retention of strength additives for pulps with different levels of refining

\begin{tabular}{ll}
\hline Pulp & Starch retention (\%) \\
\hline SR0 & 1.1 \\
SR1000 & 1.12 \\
SR2000 & 1.21 \\
\hline
\end{tabular}

explained by the difference in their starch retention. Most probably, starch amplified the effect of the other factors that were changed by refining, such as fines or swelling. However, this particular aspect is outside the scope of this paper.

Summary of the experimental results

Higher levels of refining resulted in handsheets with increased strength and stiffness, as was expected. This increase happened together with densification of the handsheets. By analyzing the changes in the pulp using the fiber characterization tools and micro-tomography, we conclude that the structural changes in the fibers upon refining are small. The changes in the detected fines fractions are also minor. However, the increased presence of fibrillary fines was detected directly through decreased freeness as observed in two different methods. 
The experimental results from adding the strength additive to the unbeaten pulp show improved strength, practically unchanged stiffness, and little densification. When adding the strength additive to the refined pulp, densification was observed and both strength and stiffness were improved. The retention of starch was not changed by refining. This means that although the total quantity of strength additives was not significantly affected by refining, the influence of starch is greater in the refined pulp.

The pulp characterization data showed that, apart from the shortening of fibers with increased refining, there is no significant difference that can be captured with these tools. In other words, we observed no change in external fibrillation, kinks, and curl of fibers with different levels of refining.

The shortening of the fibers produced an additional quantity of flake-like fines. However, the characterization devices were unable to detect the fibrillar fines, the presence of which was only indirectly captured through the dewatering tests. The fibrillary fines alone are known to have a positive impact on the sheet properties, which is the reason for the improved stiffness and strength. At the same time, the exact mechanisms behind these improvements are not completely clear because they occur in conjunction with densification, which increases the number of contacts and also changes the geometrical alignment of the fibers.

\section{Numerical simulations}

3D numerical simulations of paper have previously been used to study network properties. For example, a study simulating the wet pressing operation with the ability to calculate the shape of fibers at the contact sites was presented in (Lavrykov et al. 2012). In this study, the deformation of fibers at the bonds naturally results in a specific thickness of the network that can be used to calculate the density. In a similar study, the same simulation techniques were used to study the contribution of fiber properties to the network properties with a focus on the bending stiffness (Lavrykov et al. 2011). In these studies, the fibers were modeled using 3D solid elements. Using such 3D elements requires a fine resolution of the fiber cross-section and is computationally expensive for considering large sizes and grammages. On the other hand, it has the advantage of capturing the cross-sectional deformations of fibers, specifically at the bonds. In this work, the compliance of the bonds is captured through the penalty-based beam-to-beam constraint (Motamedian 2018; Motamedian and Kulachenko 2018).

Since the pulp characterization tools were unable to capture any significant morphological changes induced by refining, a considerable difference in mechanical response is not expected to be made due to pulp variabilities. However, for the sake of consistency, we investigated the impact of these small changes by creating networks using the characterization data corresponding to different levels of refining while keeping other properties such as density and through-thickness profile constant. Later, we also investigated the impact of the factors that could not be detected by the pulp characterization tools. This included the growth in the number of bonds due to increased density, the improved bond strength, and the increased fibrillar content with characteristic sizes outside the detectable range.

In this analysis, we will use network-level computational tools (Kulachenko and Uesaka 2012), which rely on an accurate 3D representation of the network. The method used for network generation and analysis is described below.

\section{Simulation method}

We use the pulp characterization data to create the geometry of the network. However, the characterization data are extracted from fibers in the saturated state, in which they are swollen. In the sheet-making process, the fibers are pressed and then they shrink during drying. We use the data from micro-tomography to account for drying shrinkage and the change of the width-to-height ratio of the fibers (shown in Fig. 1) due to pressing. We use a deposition technique from (Kulachenko and Uesaka 2012) following the model of (Niskanen and Alava 1994) to generate the geometry of the networks. The major steps of this procedure are as follows:

- We choose a random set of fiber geometry information from the corrected pulp characterization data and create a single fiber. This information includes the fiber length, width, width-to-height ratio, shape factor, and wall-thickness. 
- This fiber is then placed at a random location and with a random orientation on an imaginary $2 \mathrm{D}$ plane (for isotropic handsheets).

- The intersections of this newly place fiber with the previously deposited fibers (from top view) are found.

- The intersection points are raised vertically with appropriate values to avoid penetration of fibers. However, the fibers can undergo larger pressing at the bond sites and consequently, the distance between their centerlines becomes smaller. The normalized variation of the distance of crosssectional centers before and after being pressed is demonstrated schematically in Fig. 4 as the press ratio.

- The deposited fiber is then smoothed along its length. The smoothing procedure uses a given value for the maximum interface angle and it only permits the fiber segments to move upwards during the smoothing procedure to avoid penetration. The interface angle is schematically shown in Fig. 5.

- This procedure is repeated until the desired network grammage is reached.

This algorithm uses the actual corrected characterization data for fiber dimensions. This means that shortening of fibers and its effect on formation is automatically accounted for in the simulations. A sample of a generated network is shown in Fig. 6.

We used FEM (finite element method) in an implicit solution scheme to analyze the networks. To do so, the generated network was discretized using nonlinear 3-node Timoshenko/Reissner beam elements (Ibrahimbegović 1995) with either solid or hollow rectangular cross-sections. The inter-fiber
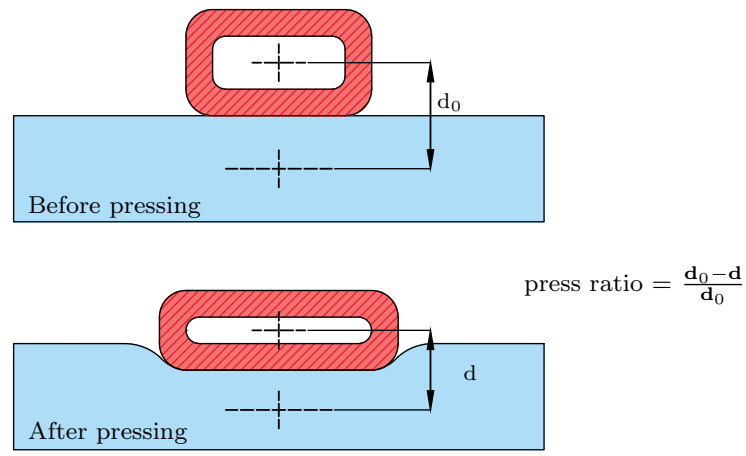

Fig. 4 Schematic representation of the parameter press ratio used in numerical generation of networks

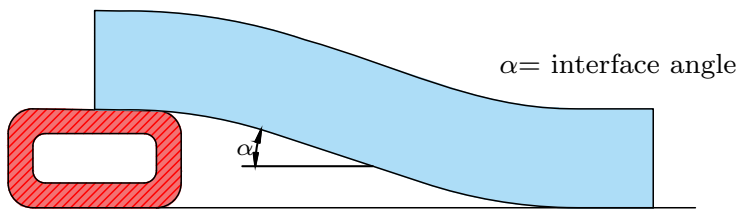

Fig. 5 Schematic representation of the parameter interface angle (Borodulina et al. 2016) used in numerical generation of networks

bonds were simulated as bonded (adhesive) beam-tobeam contact elements (Motamedian 2016, 2018) with a separation criteria. A more detailed description and demonstration of application of the formulations can be found in (Borodulina et al. 2016; Motamedian and Kulachenko 2018, 2019). The geometric, mechanical, and discretization parameters that were used in the simulations are listed in Table 10.

One of the known effects of the fibrillar fines is forming bridges between the neighboring crossing fibers and reinforcing the bonds as shown in Fig. 7a. In some cases, this can result in the formation of webs of fines, as shown in Fig. 7b. Note that the SEM images of Fig. 7 have only captured the fines on the surface while the inner structure is more intricate. To mimic the behavior of fines in the simulations, we introduced a large number of truss elements, which are shown as blue components in Fig. 8. These truss elements have two nodes with three translational degrees of freedom at each node and they solely transmit load in axial tension. The nodes of these elements are connected to the existing nodes of the beams representing the fibers. Owing to their small dimensions, the fibrillary particles tend to converge to the bonds according to literature. To represent this placement, the deposition of the fibrils is made by first selecting an arbitrary node and then finding a second node within a sphere of a designated radius. The sphere radius equals the maximum fine length and it is centered on the first node, which is randomly chosen. This distribution approach yields a fibrillary deposition in which most of the fines gather near the bonds between fibers which is consistent with what is reported in literature. Using this method, no additional degrees of freedom are added to the system. For clarity, this approach is visualized in Fig. 9. The properties of the elements used to simulate the fines can be found in Table 10 . 


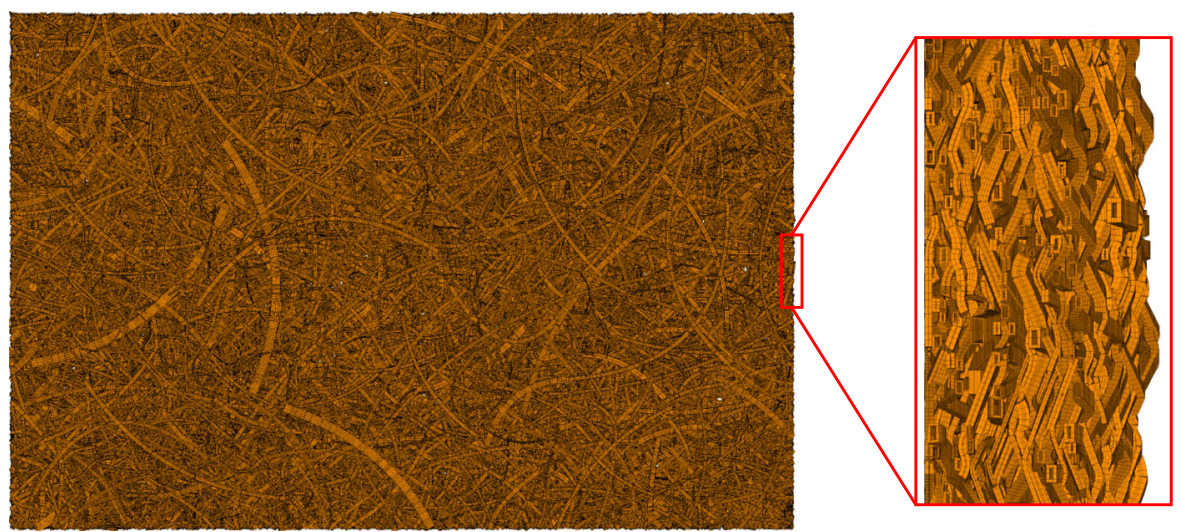

(a)

(b)

Fig. 6 A sample of a numerically generated network, a in-plane view, and $\mathbf{b}$ thickness view

The effect of captured pulp variations

To show that the captured variability between pulps with different levels of refining do not have a large effect on the properties of the handsheets, we created five different networks using the characterization data corresponding to each level of refining (15 networks in total). We considered similar other properties for these networks. The resulting averaged stress-strain curves are shown in Fig. 10. These results show that the pulp variations captured through characterization do not have a considerable effect on the properties of the handsheets. Given that no considerable differences were revealed, in the generation of the subsequent networks we used a set of pulp data consisting of the combined data captured for all three pulps.

The effect of density

It is suggested that the improvements caused by refining can mainly be attributed to the increased density (Sehaqui et al. 2013). According to the measurements shown in Table 8 , the density of handsheets is greatly affected by refining. The change in the density is mainly due to the difference in the thickness of the handsheets. According to our network generation algorithm, there are three parameters that can greatly affect the thickness of the handsheets: the width-to-height ratio of the fiber cross-sections, the press ratio at the bonded sites, and the interface angle between two bonded fibers. The data extracted from the micro-tomography images showed that neither the width-to-height ratio of free fiber segments nor the interface angle distribution are considerably affected by different refining levels. Consequently, while using the micro-tomography extracted data on width-toheight ratio and interface angle in generating networks, we focused on the press ratio at bond sites as the main reason affecting the thickness of the networks. Unfortunately, it was not possible to extract data on the press ratio parameter from tomography images due to difficulties in precisely tracking fibers at the bonded sites caused by the limited resolution of the images. To ensure the correctness of the network representation, we extracted the through thickness density profiles of the handsheets from the tomography data. In the network generation process, we used the press ratio parameter to match these density profiles and also the measured thicknesses of the handsheets. The density profiles of the unrefined and mostly refined samples, and examples of density the profiles of corresponding numerically generated networks are shown in Fig. 11.

For each level of refining five different networks are generated. The averaged resulting stress-strain curves from the analysis of the generated networks are shown in Fig. 12 together with the experimental stress-strain curves, for comparison. As can be seen in the results, although the increase in the density of the handsheets affects the strength and stiffness of the networks through the increased number of bonds, it is not sufficient to explain the total improvements. 
Table 10 Parameters and settings used in numerical simulations

\begin{tabular}{|c|c|c|}
\hline \multirow[t]{2}{*}{ Analysis } & Type & Nonlinear, implicit \\
\hline & Convergence criteria & L2 norm of residual force $<10^{-3}$ \\
\hline \multirow[t]{4}{*}{ Network } & Size & $5 \mathrm{~mm} \times 3 \mathrm{~mm}$ \\
\hline & Thickness & $374 \mu \mathrm{m}$ to $526 \mu \mathrm{m}$ \\
\hline & Number of fibers & 5300 to 6300 \\
\hline & Number of bonds & 60,000 to 90,000 \\
\hline \multirow[t]{12}{*}{ Fibers } & Element type & Timoshenko/Reissner with geometric nonlinearity \\
\hline & Number of nodes per element & 3 \\
\hline & DoF per node & 6 \\
\hline & Element size & $50 \mu \mathrm{m}$ \\
\hline & Element cross-section & Solid or hollow rectangular \\
\hline & Element cross-section & Width: $4.4 \mu \mathrm{m}$ to $95 \mu \mathrm{m}$ \\
\hline & dimensions & Height: $2.5 \mu \mathrm{m}$ to $53 \mu \mathrm{m}$ \\
\hline & Total number of elements & 75,000 to 95,000 \\
\hline & Material type & Linear elastic \\
\hline & Stiffness & $15 \mathrm{GPa}$ to $45 \mathrm{GPa}$ \\
\hline & Strength & $70 \mathrm{MPa}$ \\
\hline & Density & $1430 \mathrm{~kg} / \mathrm{m}^{3}$ \\
\hline \multirow[t]{11}{*}{ Fines } & Element type & Link \\
\hline & Number of nodes per element & 2 \\
\hline & DoF per node & 3 \\
\hline & Element size & One element per fine \\
\hline & Element cross-section & Circular \\
\hline & $\begin{array}{l}\text { Element cross-section } \\
\text { dimensions }\end{array}$ & Diameter: $1 \mu \mathrm{m}$ (varied between 0.5 to $16 \mu \mathrm{m}$ in parameter study) \\
\hline & Total number of elements & 600,000 if fines are included (varied between zero to $3,000,000$ in parameter study) \\
\hline & Matrial type & Linear elastic \\
\hline & Stiffness & (Varied between 50 and $120 \mathrm{GPa}$ in parameter study) \\
\hline & Strain to failure & $3 \%$ (varied between 0.5 and $8 \%$ in parameter study) \\
\hline & Density & $1430 \mathrm{~kg} / \mathrm{m}^{3}$ \\
\hline \multirow[t]{4}{*}{ Bonds } & Element type & $\begin{array}{l}\text { Inconsistent beam-to-beam inseparable point contact element based on closest point } \\
\text { projection }\end{array}$ \\
\hline & DoF per element & 24 \\
\hline & Penalty stiffness & $3000 \mathrm{~N} / \mathrm{m}$ \\
\hline & Failure criteria & Maximum separation distance of $2 \mu \mathrm{m}$ Borodulina et al. (2016) \\
\hline
\end{tabular}

Note: Close-to-parallel contacts (with contact angle $<2^{\circ}$ ) were neglected (less than $0.5 \%$ of the total)

The effect of inter-fiber bond strength

Refining is often described as a process that leads to increased bond area and strength. As we use a pointwise beam-to-beam contact model to represent the inter-fiber bonds, we cannot study the effect of the increased bonded area directly but rather through an indirect change of bonding properties. The increase in the bond strength can be related to the increased bonded area between fibers, which may likely happen upon densification or the use of strength additives. Consequently, we studied the effect of stronger bonds combined with the previously considered effect of density. The stress-strain curves from our analyses of the same network (only one of the networks, keeping the geometry, meshing, etc. constant), with different strengths for inter-fiber bonds, are shown in Fig. 13. As expected, the increase in bond strength improves 


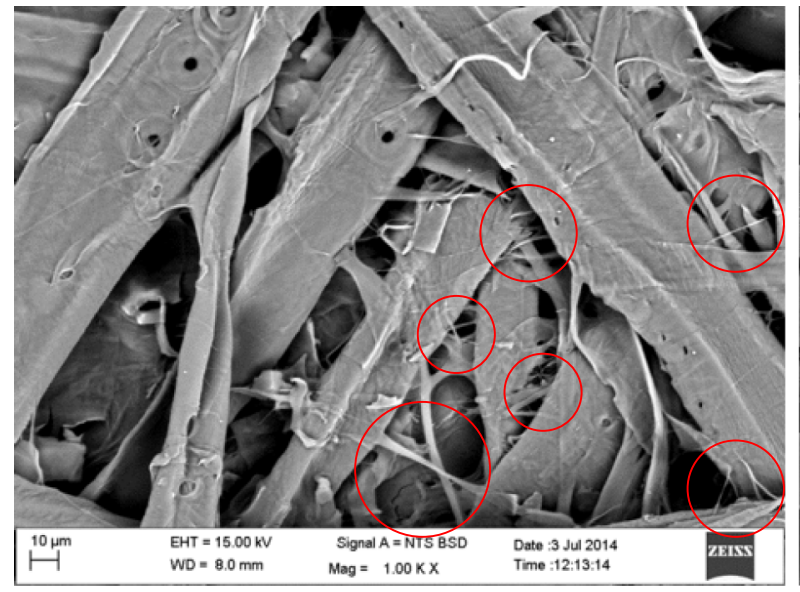

(a)

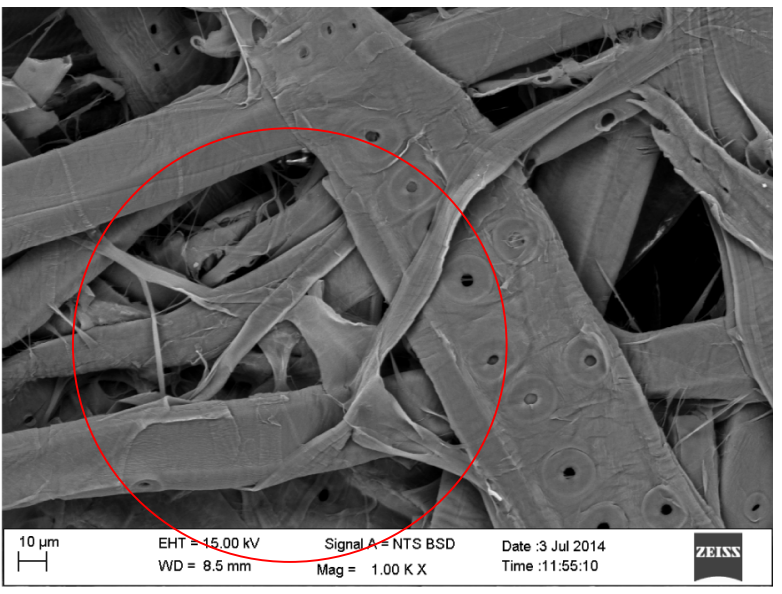

(b)

Fig. 7 SEM image of paper surface showing, a some fibrillar bridges and $\mathbf{b}$ a web structure formed by fines

Fig. 8 Representation of fibrillar bridges with (blue) link elements. (Color figure online)

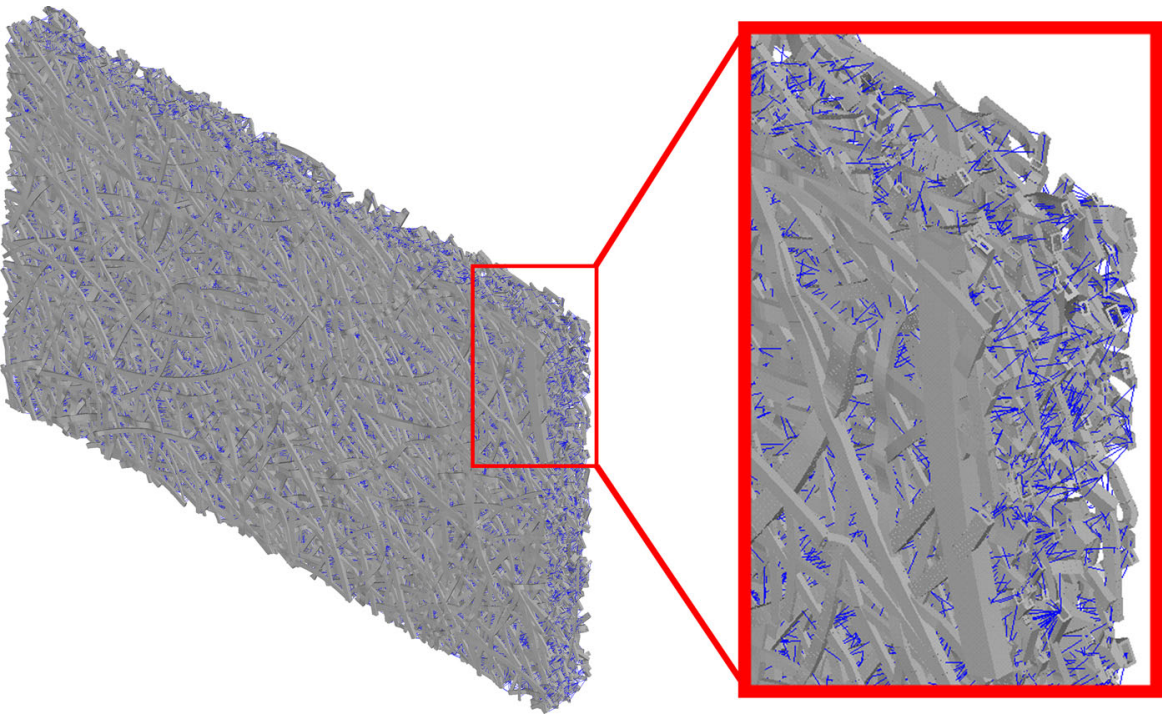

the strength of the network; however, the stiffness of the sample remains unchanged. This result is consistent with the experimental results on the handsheets from unbeaten pulp in response to the addition of bond strength additives. Those experimental results had shown that using strength additives in unbeaten pulp does not noticeably affect the density and stiffness, but it does improve the strength of paper.

The effect of fines

Previous experimental study has shown that both refining and the addition of fibrillary fines have the same effect on the mechanical properties and the dewatering characteristics of paper products (Afra et al. 2013). This suggests that the creation of fines can be a major reason behind the modifications achieved by refining. A microscopic photo of a fiber and fines of both fibrillar and chunk type can be seen in Fig. 14. To get a better understanding of the characteristics of the fines in the handsheets, microscopic images of the pulps were taken. The goal was to qualitatively compare the shape and amount of fines in the differently refined pulps. The microscopy images of the pulps were taken using an Olympus BX50 System 


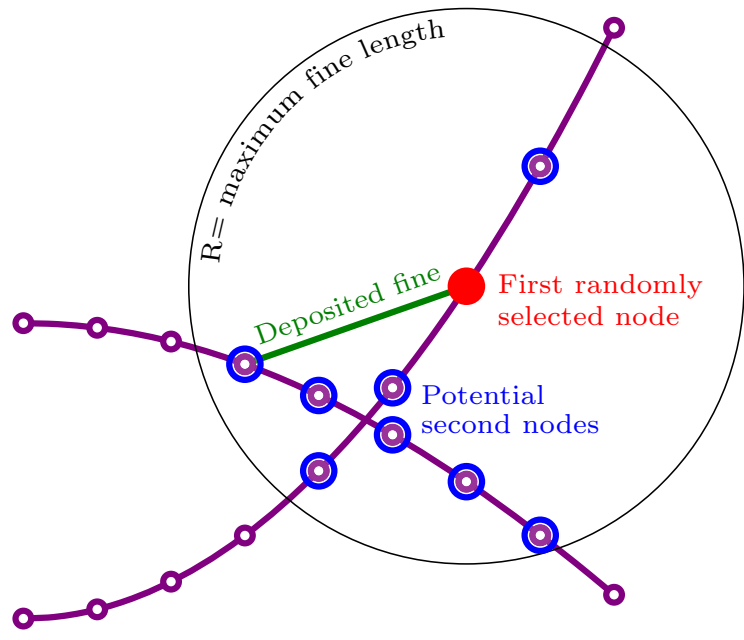

Fig. 9 Deposition of fines as fibrillar bridges

Microscope. Representative microscopic images of the pulps can be seen in Fig. 15.

Although we can see from the microscopic images that refining has resulted in an increased fine percentage, the amount and size of fibrillar fines in our pulps are not known due to the limited resolution of measuring devices. Consequently, we conducted a parameter study to investigate the effect of fine size, the mechanical properties, and the percentage on the stiffness and strength of the networks. We have chosen the reference set of values for all parameters as presented in Table 11, and investigated the effect of varying each of those parameters while keeping the others as the reference value. The range of studied variations are given in Table 11 . We have added the fines to a network corresponding to the unrefined sample, unless stated otherwise.

\section{The effect of fine diameter}

The pulp characterization tools have limited resolution and the fines below certain size will not be detected. This fact was previously reported in the literature (Brodin and Eriksen 2014). In this study, we used a constant mass fraction of the fines equal to $3 \%$ and varied the diameter of the fines. We generated a base network and assumed a specific diameter size for fine cross-sections. We started adding link elements to the network until the target mass fraction was reached. We then repeated the same procedure for different diameters of fines. The resulting stress-strain curves from the analysis of the mentioned networks are shown in Fig. 16. As seen in the figure, fines with large diameters of 16 or $10 \mu \mathrm{m}$, which are on the verge of what can be detected by the characterization tools, have almost no effect on the properties of the networks and fines with smaller cross-sections, which are in fact not detected by the characterization devices, have the

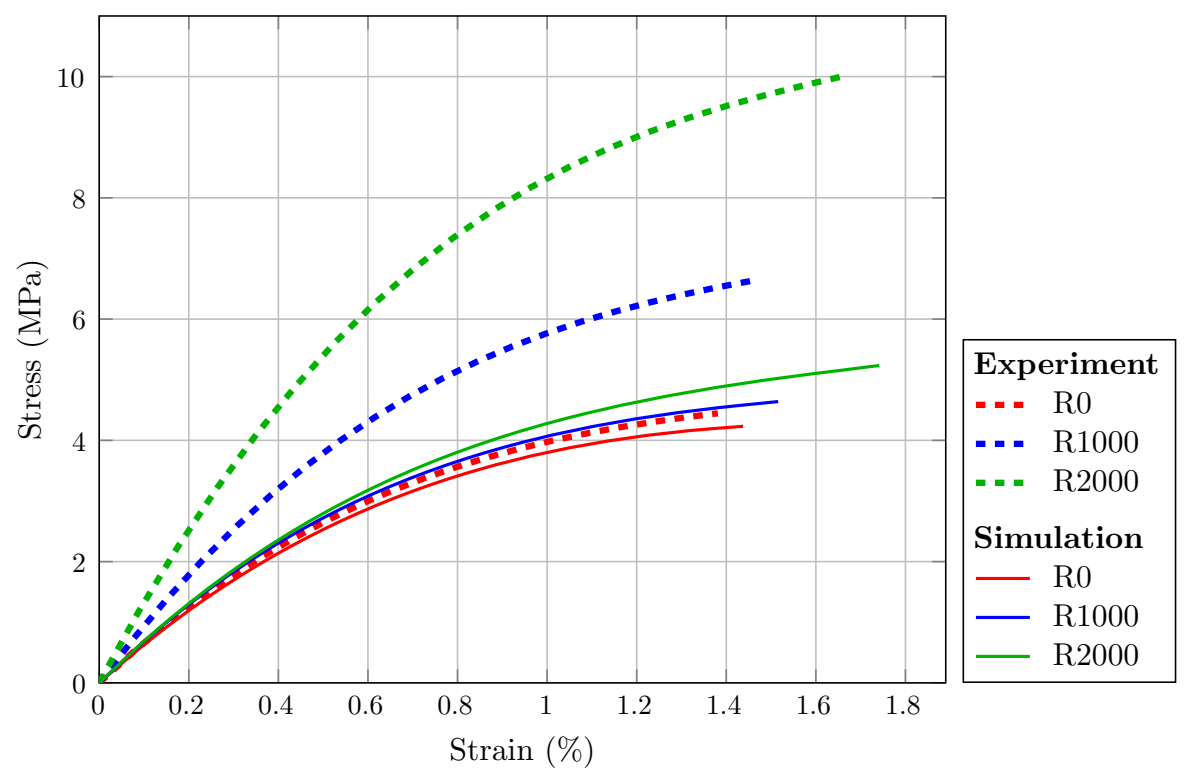

Fig. 10 The effect of pulp variations captured through pulp characterization on the simulated stress-strain curves in comparison with the experimental results 


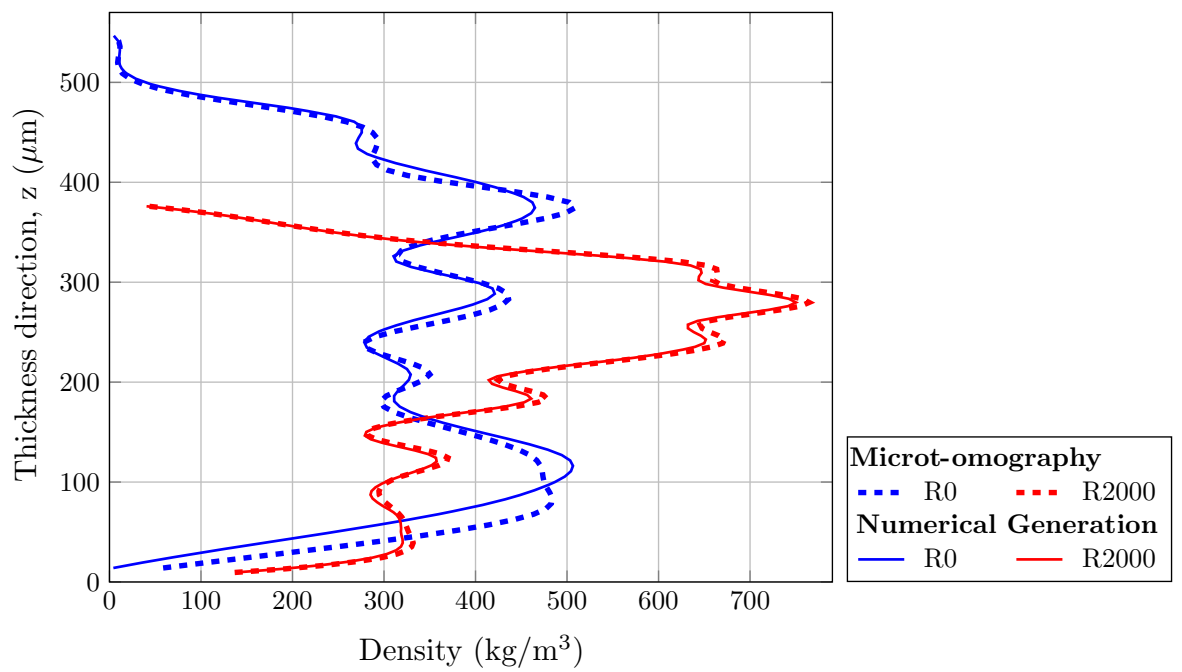

Fig. 11 Density profiles of unrefined and mostly refined handsheets from tomography data and numerical network generations

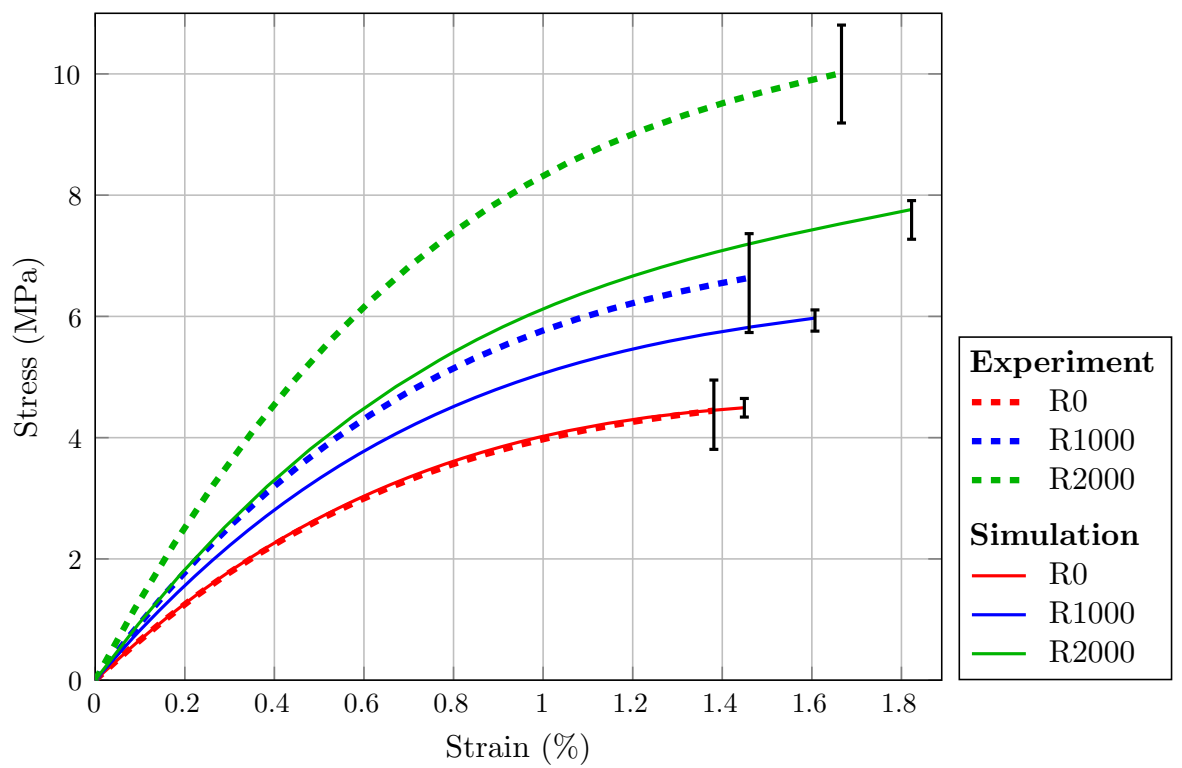

Fig. 12 Effect of density on the simulated stress-strain curves in comparison with the experimental results. The bars show the maximum and minimum of the strength results from 10

largest impact on both the strength and the stiffness of the networks. As we have considered a fixed mass percentage of fines, decreasing the fine diameter results in a large increase in the number of fines. This leads to a more effective distribution of fines, and better collective stiffening and strengthening of the network, especially close to the bonded sites where most of the fines are located. experimental or 5 numerical samples for each density and the curves represent the averages

\section{The effect of fine fraction}

For this part of the study, fines with the diameter of $1 \mu \mathrm{m}$ were added to a base network (with a thickness corresponding to the experimental handsheet from the unrefined pulp, R0) and a denser network (corresponding to the handsheet from the mostly refined pulp, R2000) at different mass fractions. The results in response to the addition of fines are shown in Fig. 17. 


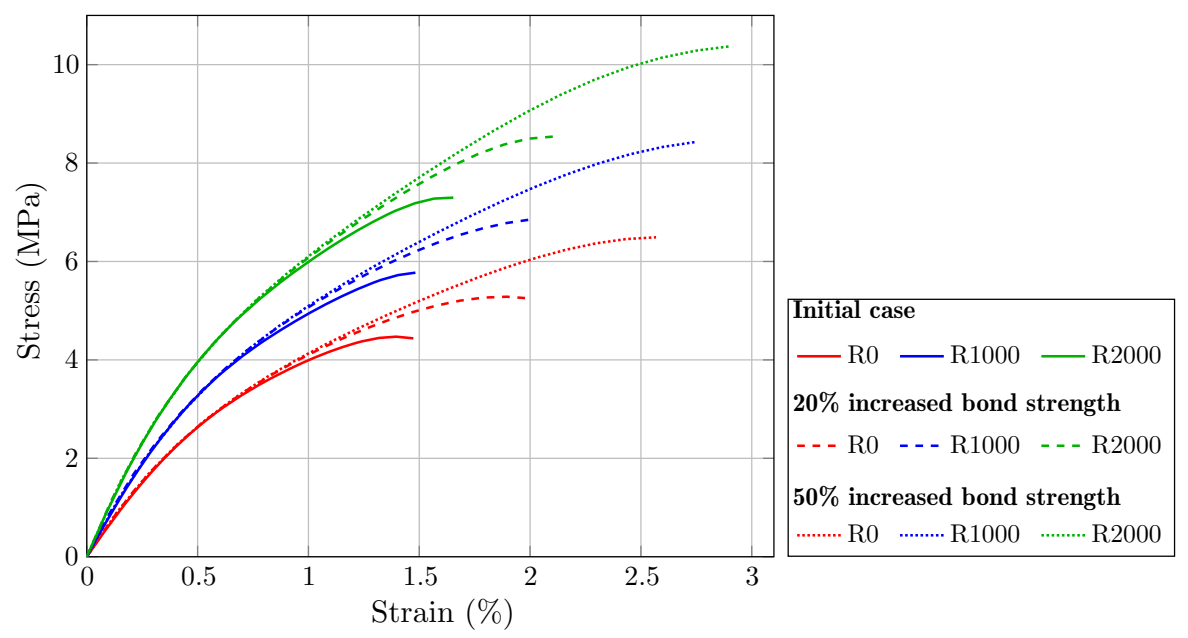

Fig. 13 Effect of bond strength on simulated stress-strain curves

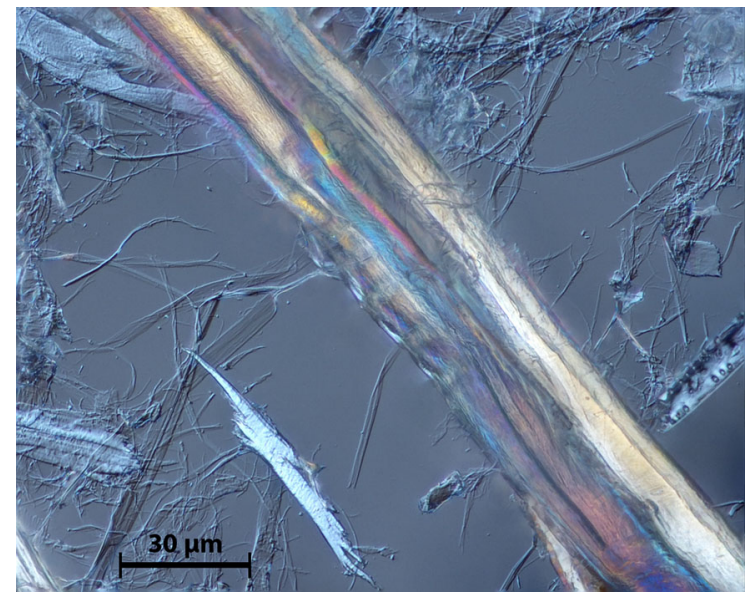

Fig. 14 Microscopic images of pulp showing a fiber and some fines

The baselines indicate the experimental results for both stiffness and strength in case of the mostly refined and densified sheets. Unless the densification is not taken into account, the experimentally measured stiffness cannot be matched within the reasonable

Fig. 15 Microscopic images of differently refined pulps
Table 11 Initial parameter values and the range of variations in the fine parameter study

\begin{tabular}{lcc}
\hline Parameter & Initial value & Variation range \\
\hline Fine diameter $(\mu \mathrm{m})$ & 1 & $0.5-16$ \\
Fine length $(\mu \mathrm{m})$ & 100 & $20-200$ \\
Fine stiffness $(\mathrm{GPa})$ & 70 & $50-120$ \\
Fine strain to failure $(\%)$ & 3 & $0.5-8$ \\
Fine mass percentage $(\%)$ & 3 & $0-10$ \\
\hline
\end{tabular}

range of fines fraction. This indicates that accounting for densification is important. Obviously, there is a direct relationship between the fines content and the amount of refining, which is consistent with previous studies (Kibblewhite 1972) but was not detected by the tools used for the pulp characterizations. The degree of the change in response to adding fines for both the stiffness and strength is comparable with the findings in which controlled amounts of fibrillar fines were added to the pulp (without refining) to improve the

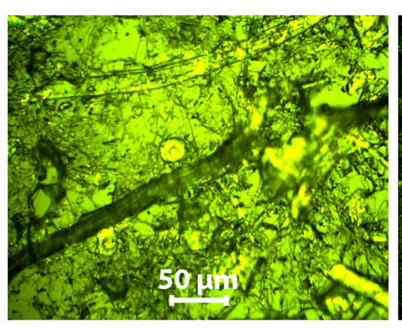

(b) R1000

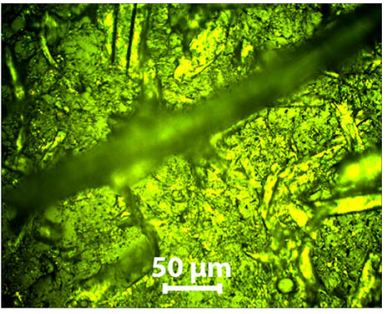

(c) R2000

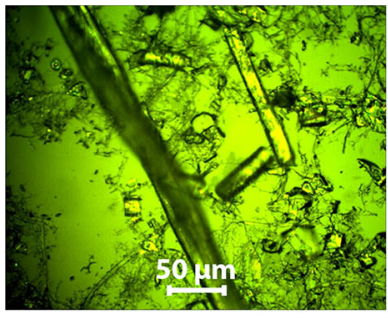

(a) R0 


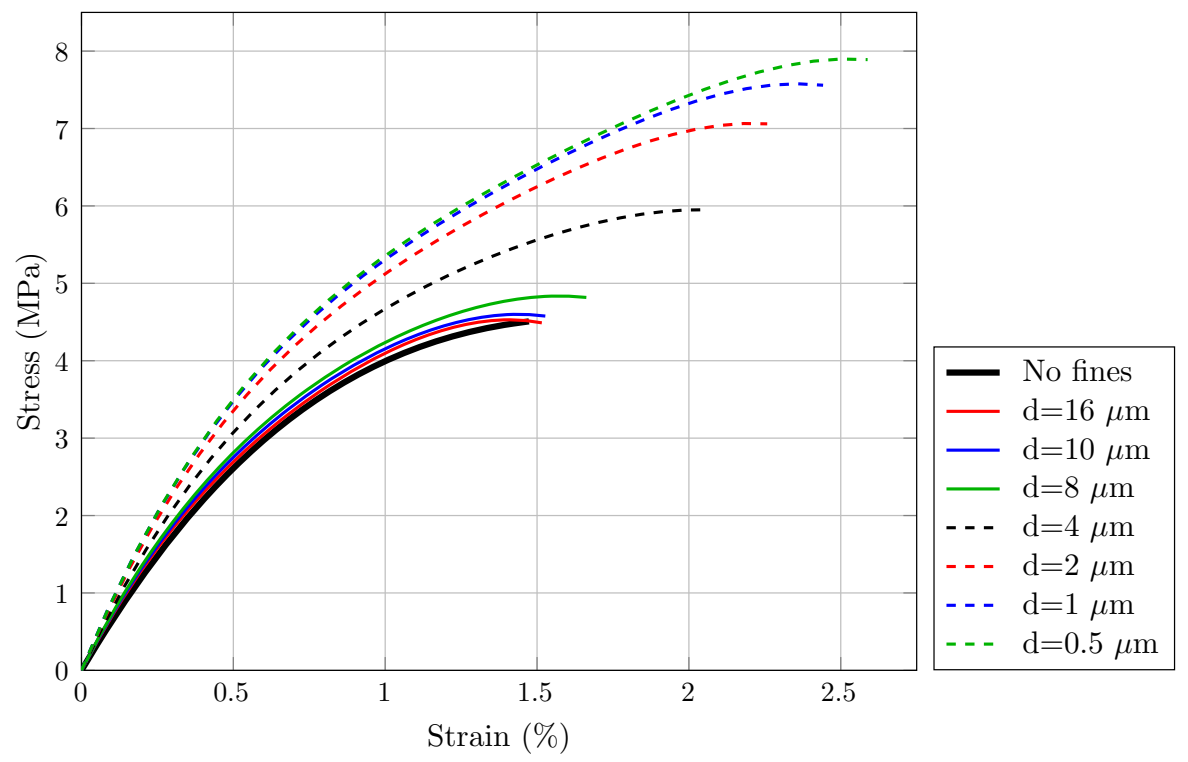

Fig. 16 Effect of fine diameter on simulated stress-strain curves

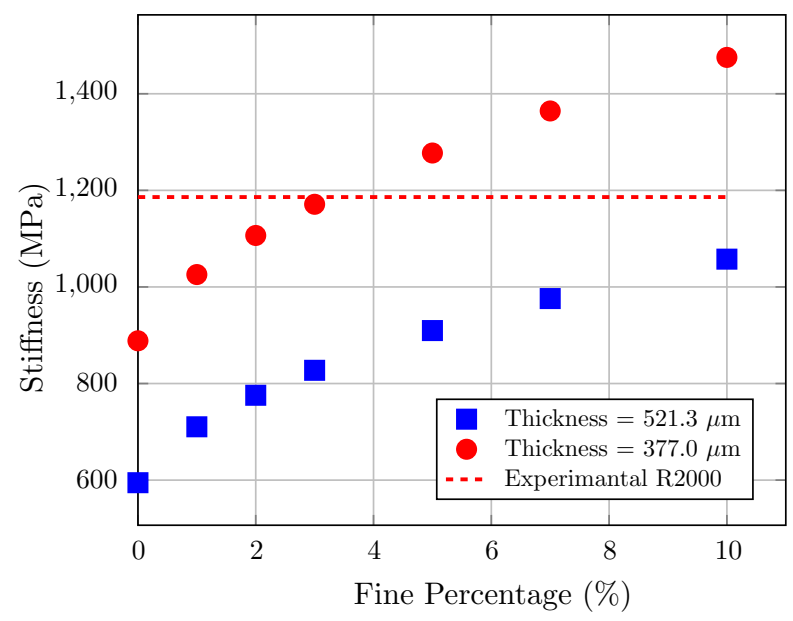

(a)

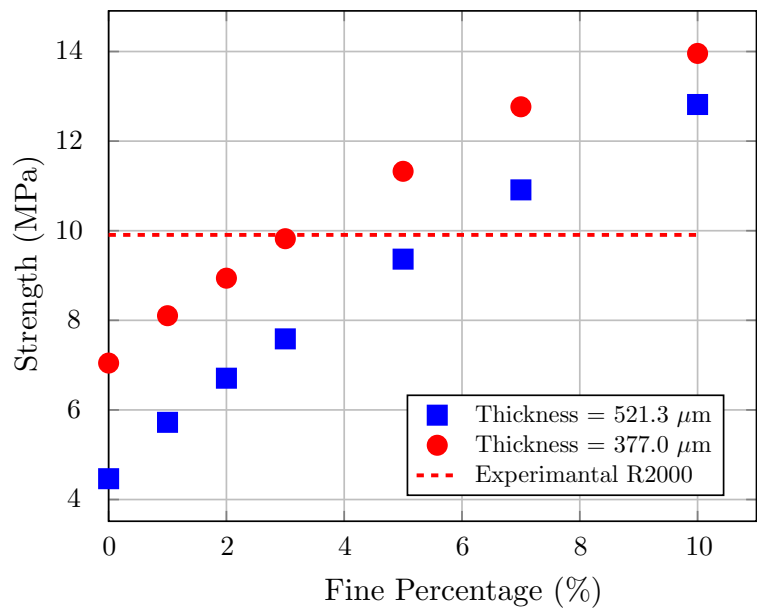

(b)

Fig. 17 Effect of fine mass percentage on a stiffness and $\mathbf{b}$ strength of networks

strength and stiffness (Boufi et al. 2016; Johnson et al. 2016; Luukko and Paulapuro 1999).

We can now shed the light on the exact mechanisms brought by fines through observing how the strain energy is partitioned between different forms of deformation. We separated the energy into elongation and bending (stored in the fibers), inter-fiber bonding and fines. The bonding energy is collected from the penalty-based contact elements. The other forms of deformations, including torsion and shear, are small and presented combined. The computed partitioning is shown in Fig. 18, where the strain energy output from the simulations of a network without and with $3 \%$ fines are compared. In both cases, most of the energy is stored in the longitudinal deformation. Given that fines act as bridges connecting fibers together, it is not surprising that the greatest effect they have is on the strain energy stored in the bonds. They also help in immobilizing the fibers, and therefore, also reduce the bending energy.

Other than carrying part of the load applied to the network, an increased amount of fines helps to smooth 


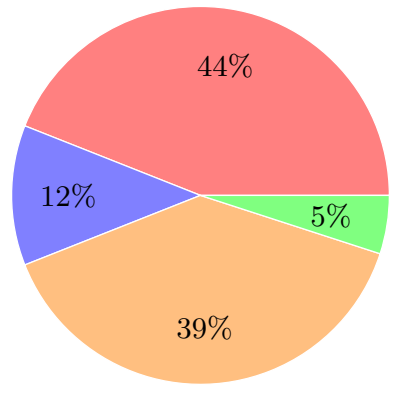

(a) Without fines

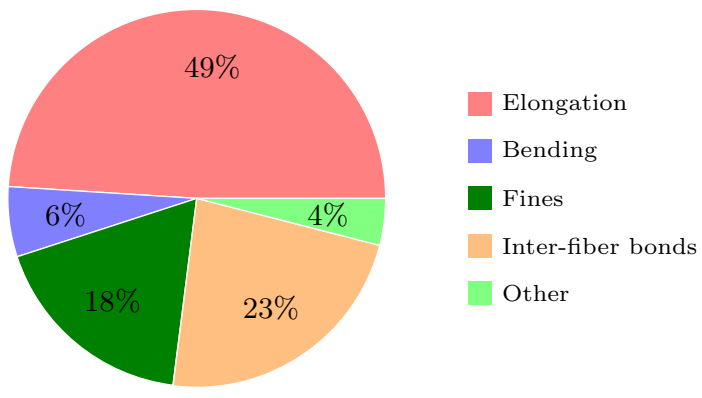

(b) With $3 \%$ fines

Fig. 18 Strain energy stored in different components of the network in $\mathbf{a}$ absence and $\mathbf{b}$ presence of fines

the strain field, which in turn can lead to the higher load capacity of the network. Figure 19 shows the strain localization from simulations of networks with different fine content.

Scattering coefficient is related to the total specific surface area and has traditionally been used to assess the degree of bonding. It was shown that fines are able to reduce the scattering coefficient at constant density (Lehtonen 2004). This was linked to the higher number of smaller pores resulted by the addition of fines at constant pore volume. Using experimental methods, separating out fiber fractions and doing hot wet-pressing, Lehtonen also concluded that fines ensure better stress transfer between bonded fibers and this effect is activated during wet-pressing. It collaborates well with the finding of this study.

\section{The effect of maximum length of fines}

Previous study has shown that the length of fines increases with the amount of energy used in refining
(Retulainen et al. 1993). In this section, we again consider a fixed mass fraction of fines equal to $3 \%$; however, we study the effect of maximum length of fines. Increasing the maximum length combined with the assumed mechanism of fine distribution will yield more fibrillar fines connecting distant regions of the fibers. The results from this study are shown in Fig. 20. It can be seen that the increase in the length of fines does not give a consistent trend. Increasing the maximum length has a positive effect on the strength of the networks up to a certain value between 50 and $100 \mu \mathrm{m}$ and afterwards the effect becomes negative.

Increasing the length of fines results in fewer fines with the given fines fraction; however, this reduction is not as drastic as the in case of increasing the diameter. This reduction in the number of fines tends to reduce the improvement in the strength and stiffness. Meanwhile, longer fines can connect fibers at longer distances, which can contribute to better stiffness or strength improvement. The results show that the positive effect of increased length is more dominant
Fig. 19 Effect of fine percentage on stress localization (from numerical simulations)

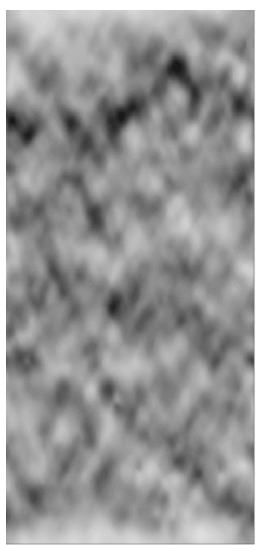

No fines

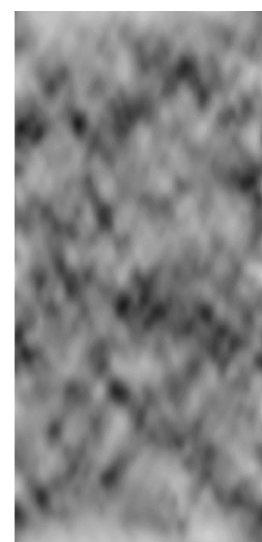

$1 \%$ fines
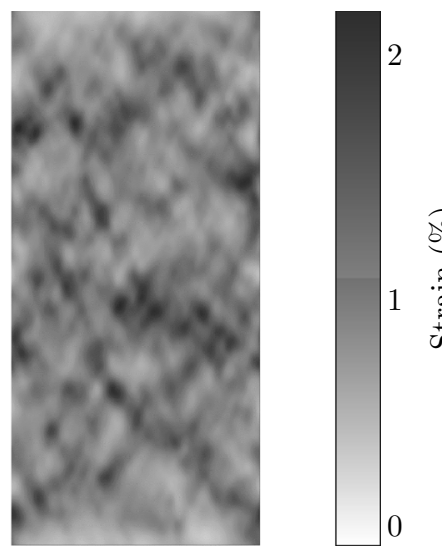

$2.5 \%$ fines 


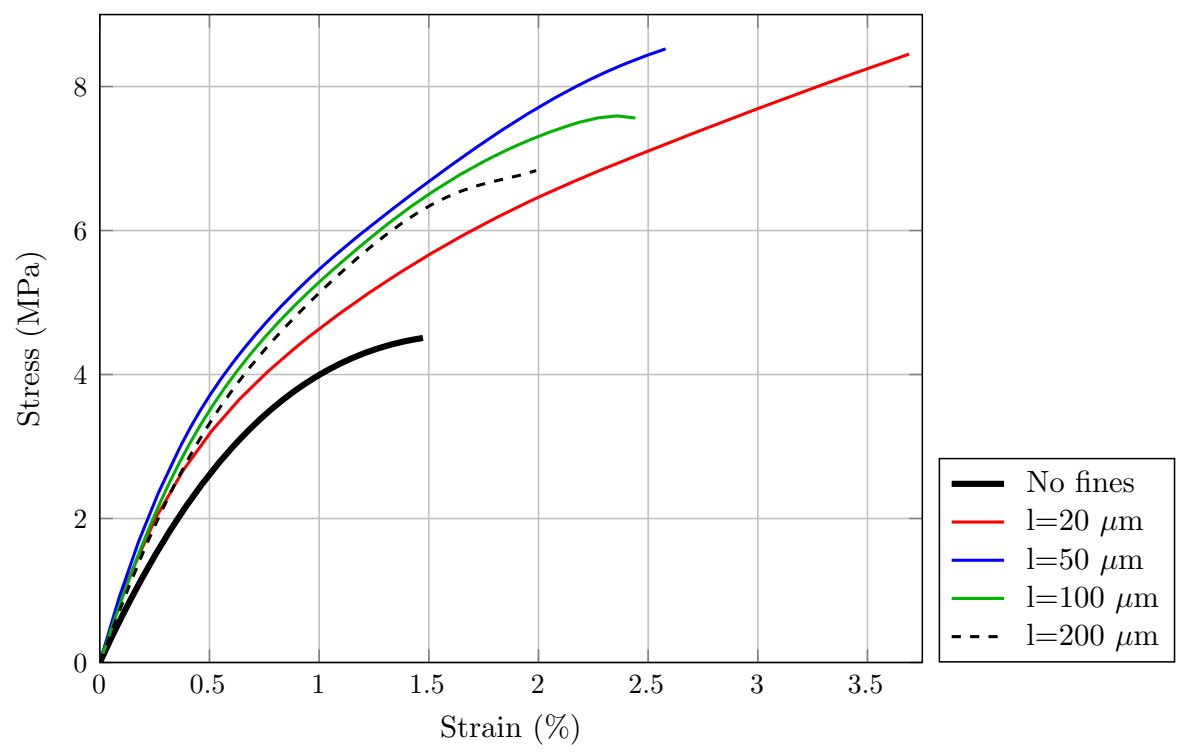

Fig. 20 Effect of fine length on simulated stress-strain curves

to a certain value, after which the negative effect takes over. These results also suggest that the main effect from the fines comes through the collective reinforcement of the bond surroundings.

\section{The effect of fine strength and stiffness}

In this part, we study the effect of fine strength and stiffness on the strength and stiffness of the networks, separately. The stiffness of the fines depends on their type, while the strength is dependent on the bond between fines and fibers. The results shown in Fig. 21 correspond to varying the elastic moduli in the range of 50-120 GPa for the fines, while keeping all of the other properties of the networks intact. We have used maximum strain as the failure criteria for fines. Upon reaching this strain, the fines are behaving ideally plastic, that is, without an incremental addition of stress upon increased strain. The effect of varying this failure criteria from a maximum allowable strain of $0.5 \%$ to $8 \%$ is shown in Fig. 22 .

In case of increased stiffness with a given strain-tofailure of $3 \%$, both the stiffness and the strength increased. The increase of the strength can be explained by the fact that fines can store more energy prior to failure. A similar effect is achieved by increasing the strain to failure. At the same time, increasing the strength of fines while keeping their stiffness unchanged does not affect the stiffness of the network because there are very few fines broken in the initial part of the loading with the property range used in the study.

\section{Conclusion}

In this study, we investigated the effects induced by PFI refining through experimental and numerical investigation of handsheets produced from pulp subjected to different degrees of refining. Mechanical testing of the handsheets showed that refining, expectedly, increased strength and stiffness, as well as sheet densification.Although the pulp characterization tools did not reveal significant differences in the geometry of fibers or presence of fines in response to refining, the freeness testing suggested a considerable modification in the pulps. By engaging micromechanical simulations, we showed that while increased density is a major reason for the improvement in the strength and stiffness of the handsheets, it cannot solely explain the degree of the change observed in the mechanical tests.

We studied the role of the fines in altering mechanical properties with a specific focus on the morphology of the fine fractions. We found that the presence of fines can significantly change both the stiffness and the strength, independent of the density change. More specifically:

- Fines with diameters below the resolution of the characterization devices have a greater influence at 


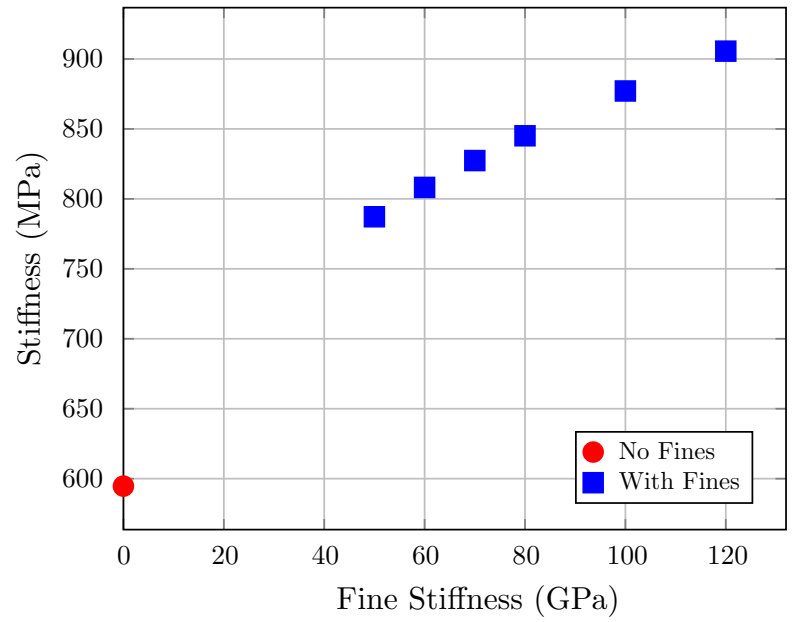

(a)

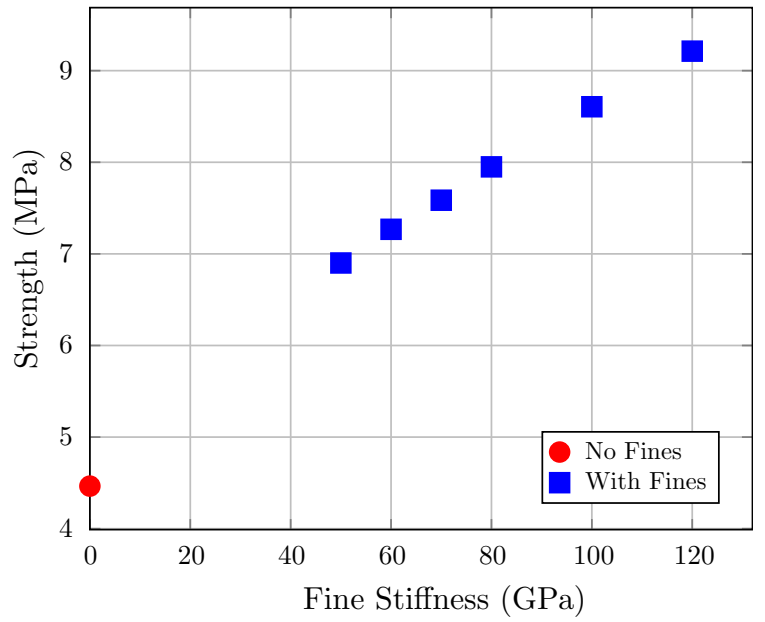

(b)

Fig. 21 Effect of elastic modulus of fines on a stiffness and $\mathbf{b}$ strength of networks

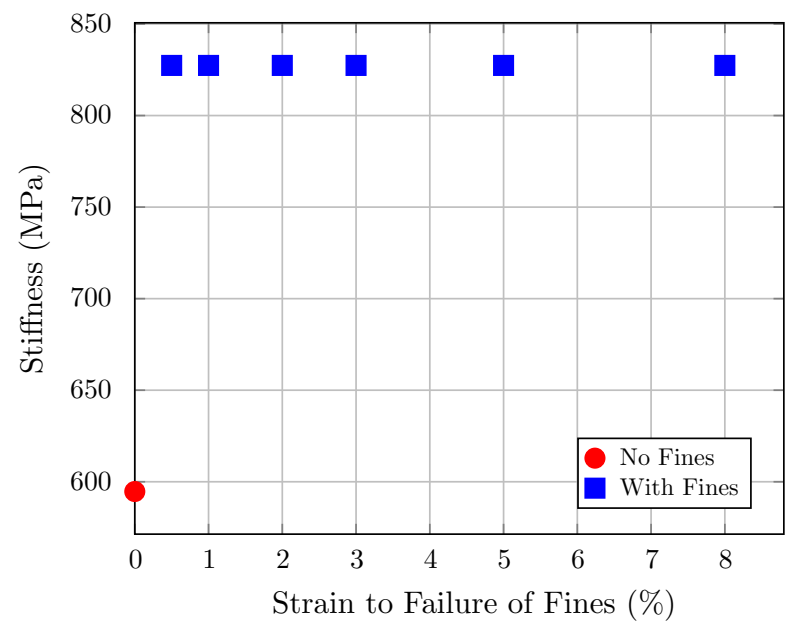

(a)

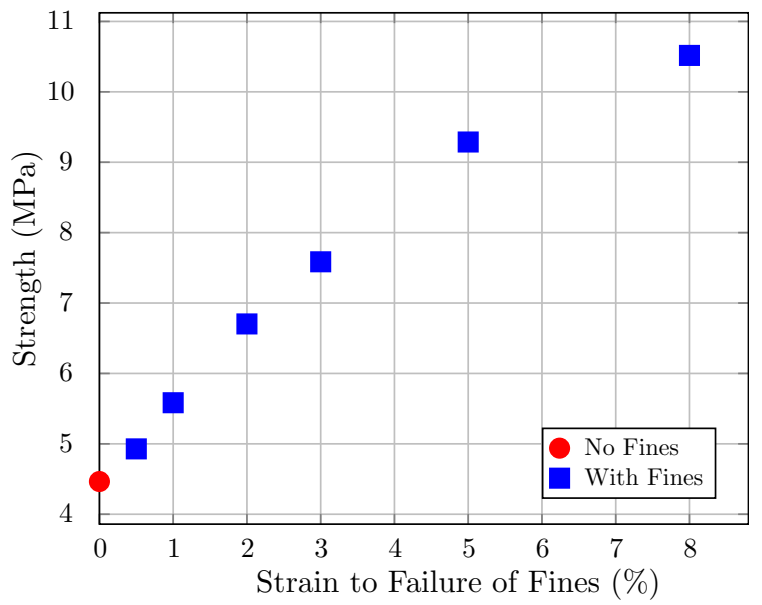

(b)

Fig. 22 Effect of strain to failure of fines on a stiffness and $\mathbf{b}$ strength of networks

a given volume fraction. The main mechanism of improvement is the collective reinforcement and stiffening of the bonds.

- Increasing the length of the fines up to a certain value with a given volume fraction improves the stiffness and strength of fiber networks because these fines can bridge more distant fibers. However, further increasing the length has an opposite effect since longer fines (resulting in their lower amount with the given volume fraction) cannot significantly change the properties as the collective action is required.

- Even low volume fractions of fines affect the stiffness of the network, however, unless the fines are sufficiently well-bonded, the strength of the sheet is not affected.

We can explain the experimentally observed effects of refining by the combined contribution of densification and presence of fines below the resolution of the stateof-the-art characterization tools.

Finally, we have also determined that an increase in bond strength can only lead to a greater strength on the sheet level and does not affect the stiffness of the samples. This agreed with the experimental results achieved by adding bonding agents to the unrefined pulp during sample production and observing improved 
strength and unchanged stiffness. At the same time, adding bonding agents to the refined pulp improved both the stiffness and the strength. This suggests a collaborative effect of fines and strength additives.

Acknowledgments Support from the Federal Ministry of Economy, Family and Youth and the National Foundation for Research, Technology and Development, Austria, is gratefully acknowledged.The computational resources were provided by the Swedish National Infrastructure for Computing (SNIC) at HPC2N, Umeå (Project SNIC2017-1-175).We also acknowledge Mats Fredlund at StoraEnso for the valuable help in the project, Sofia Sandin for the SEM image of the network and microscopy images of the the furnish (Figs. 7, 15), Bergman Labora for her help with the microscopy images of the fiber (Fig. 14), and Wolfgang Fischer at Graz University of Technology and Timo Kuntzsch at

Papiertechnische Stiftung (PTS) for their help with fiber characterization. VINNOVA (Grant No. 2016-02702).

Open Access This article is distributed under the terms of the Creative Commons Attribution 4.0 International License (http:// creativecommons.org/licenses/by/4.0/), which permits unrestricted use, distribution, and reproduction in any medium, provided you give appropriate credit to the original author(s) and the source, provide a link to the Creative Commons license, and indicate if changes were made.

\section{Appendix: Pulp characterization data}

See Figs. 23, 24, 25, 26, 27, 28, 29, 30 and 31

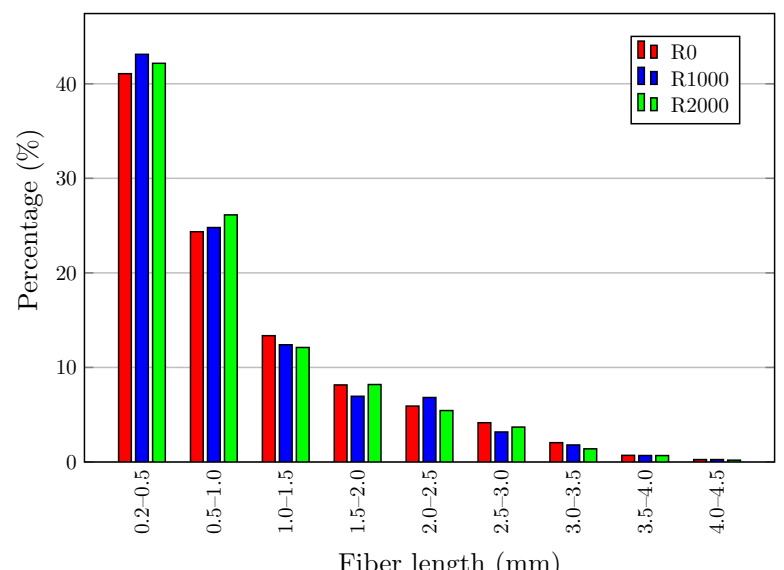

Fiber length (mm)

(a)

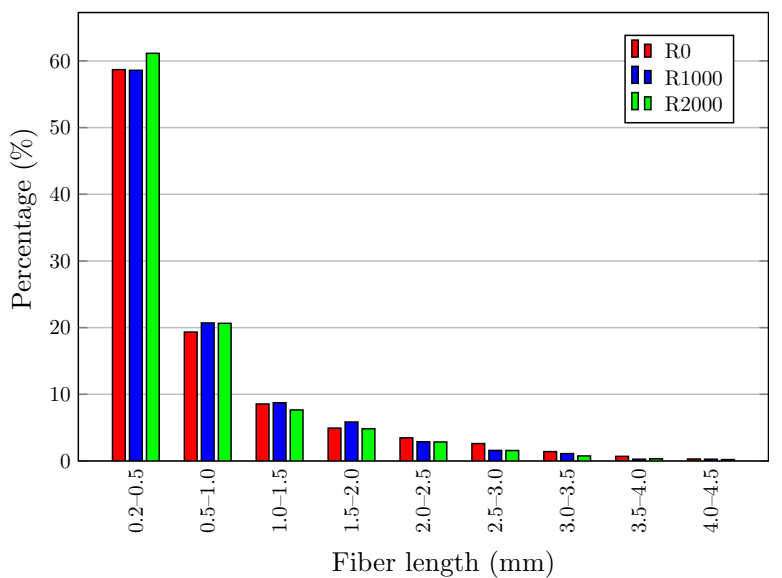

(b)

Fig. 23 Length distribution of fibers, measured by a Kajaani and b L\&W Pulp Tester
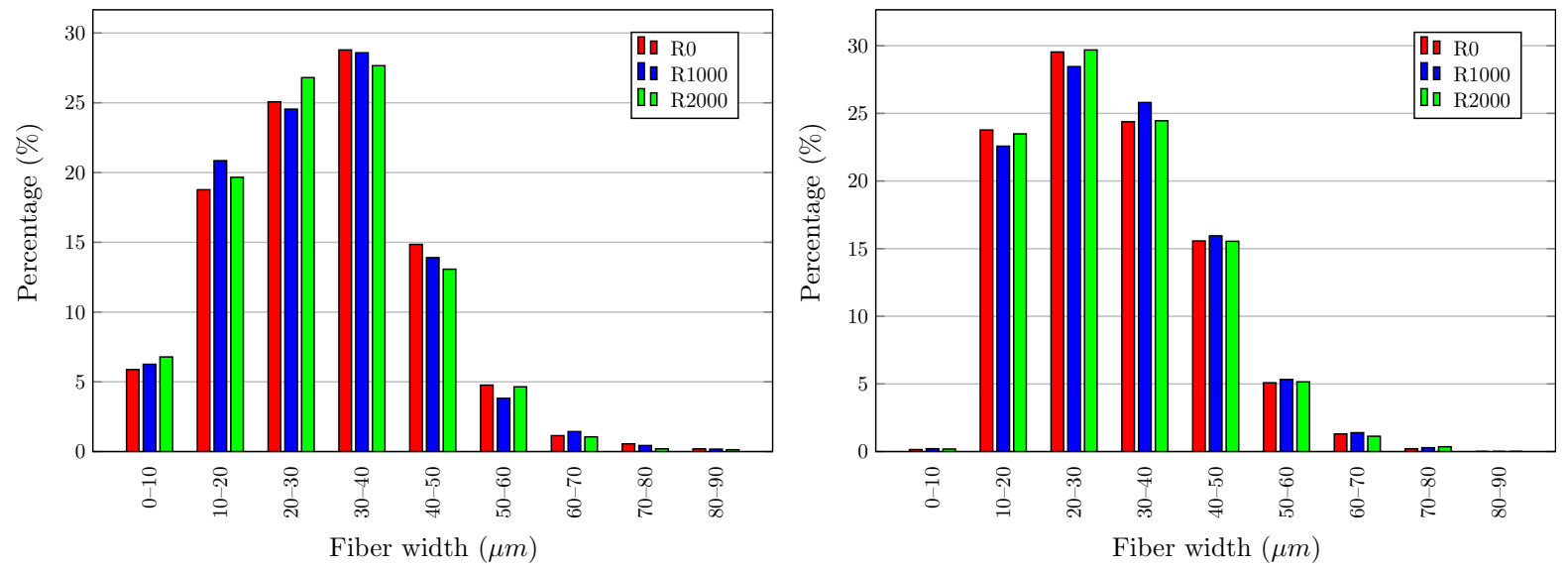

Fig. 24 Width distribution of fibers, measured by a Kajaani and b L\&W Pulp Tester 


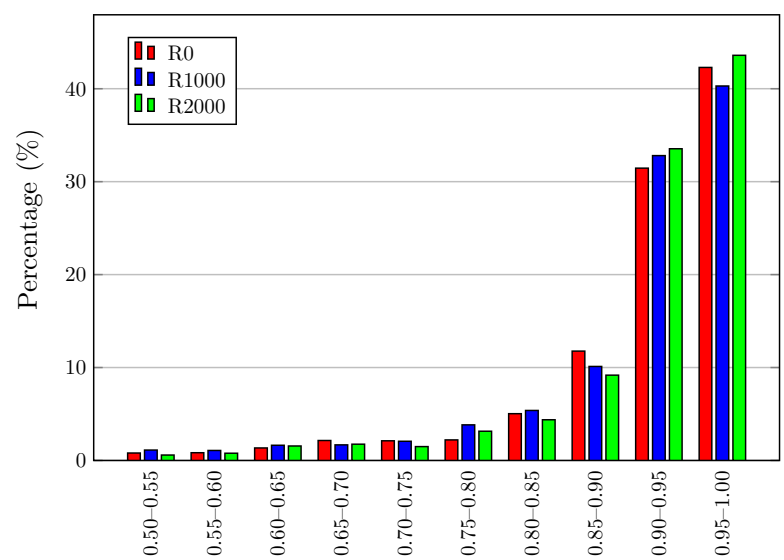

Fiber shape factor (-)

(a)

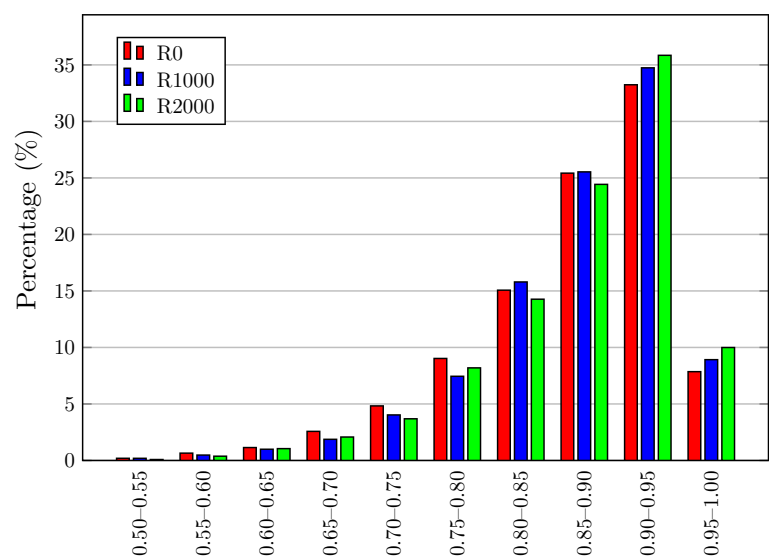

Fiber shape factor (-)

(b)

Fig. 25 Shape factor distribution of fibers, measured by a Kajaani and b L\&W Pulp Tester

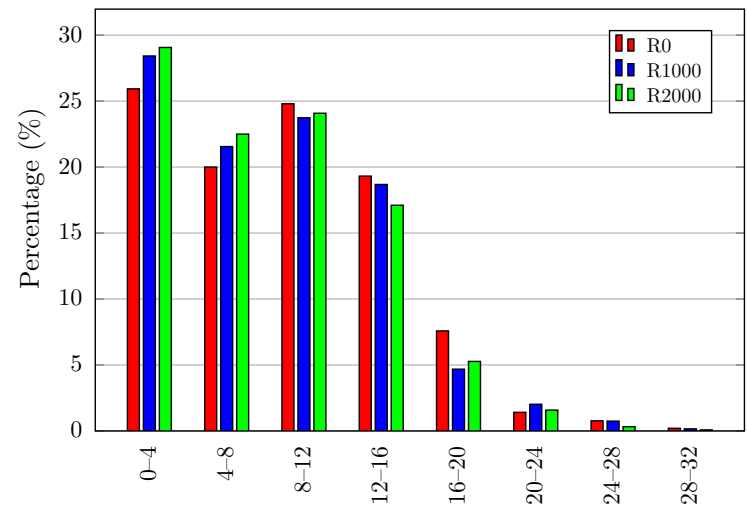

Fiber wall-thickness $(\mu m)$

Fig. 26 Wall-thickness distribution of fibers, measured by Kajaani

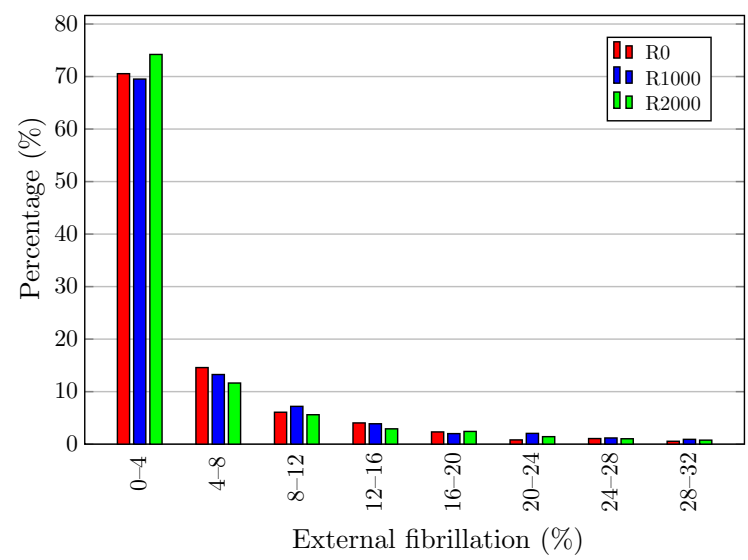

Fig. 27 External fibrillation distribution of fibers, measured by Kajaani

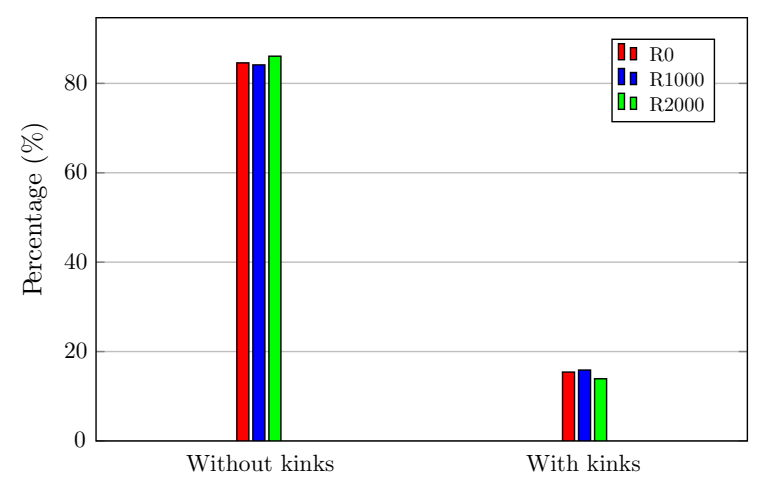

Fig. 28 Comparison of the percentage of kinked and kink-free fibers from measurements by Kajaani 


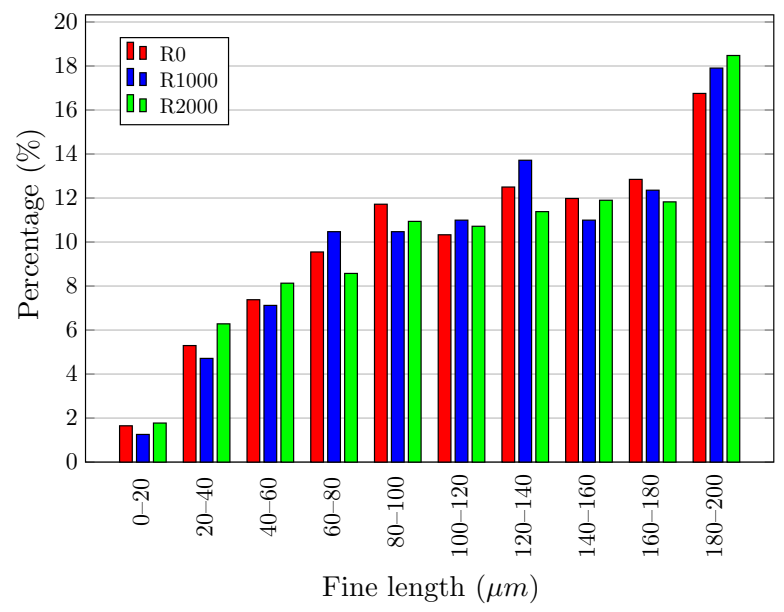

(a)

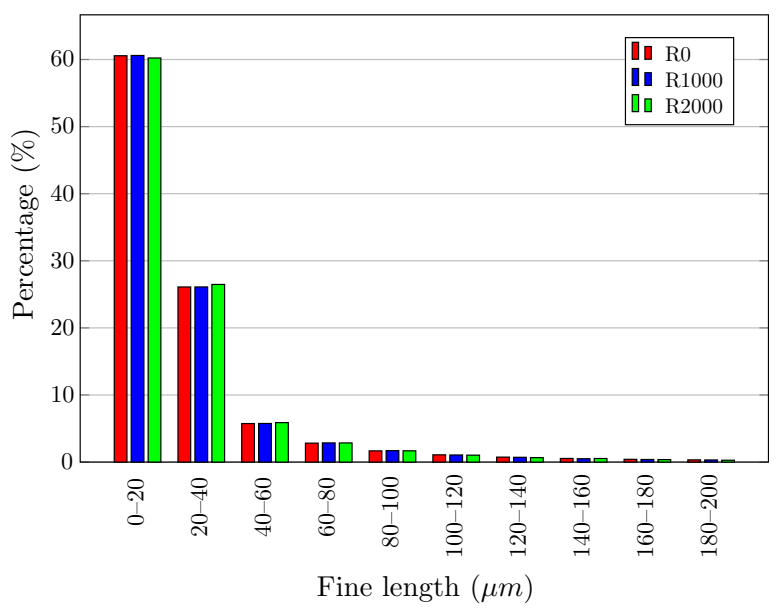

(b)

Fig. 29 Length distribution of fines measured by a Kajaani and b L\&W Pulp Tester

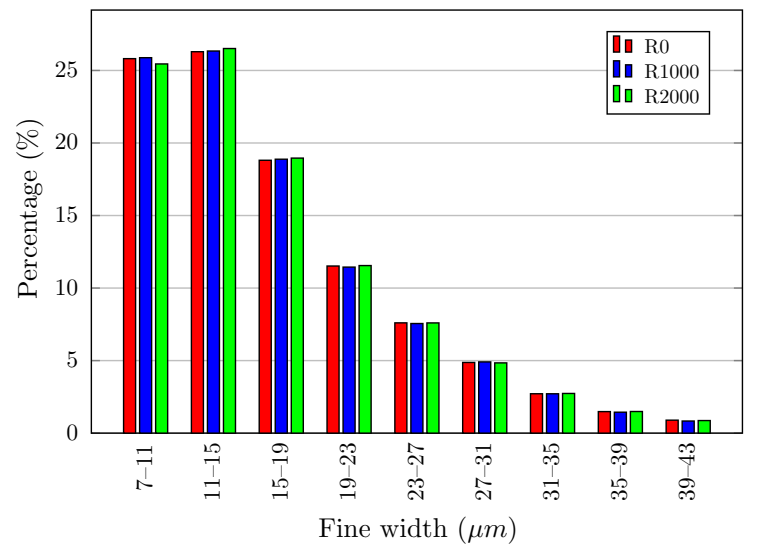

Fig. 30 Width distribution of fines measured by L\&W Pulp Tester

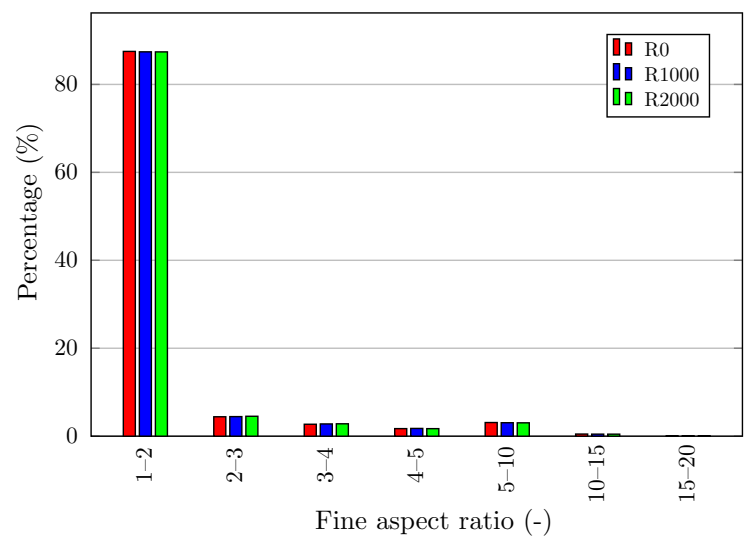

Fig. 31 Aspect (Length-to-width) ratio distribution of fines measured by L\&W Pulp Tester

\section{References}

Abitz P, Luner P (1989) The effect of refining on wet fibre flexibility and its relationship to sheet properties. In: Fundamentals of papermaking, vol 1 of transactions of the ninth fundamental research symposium held at Cambridge: September 1989. Mechanical Engineering Publications Limited, pp 67-86

Afra E, Yousefi H, Hadilam MM, Nishino T (2013) Comparative effect of mechanical beating and nanofibrillation of cellulose on paper properties made from bagasse and softwood pulps. Carbohydr Polym 97(2):725-730

Alexander SD, Marton R, McGovern SD (1968) Effect of beating and wet pressing on fiber and sheet properties. ii. Sheet properties. Tappi J 51(6):283-288

Alince B, Porubská J, van de Ven TGM (2001) Effect of model and fractionated TMP fines on sheet properties. In: The science of papermaking, vol 2 of transactions of the 12th fundamental research symposium held in Oxford: September 2001. Mechanical Engineering Publications Limited, pp 343-1355

Biermann CJ (1996) Refining and pulp characterization. In: Biermann CJ (ed) Handbook of pulping and papermaking, second edn. Academic Press, Cambridge, pp 137-157 chapter 6

Bither TW, Waterhouse JF (1992) Strength development through refining and wet pressing. Tappi J 75(11):1-9

Borodulina S, Motamedian HR, Kulachenko A (2016) Effect of fiber and bond strength variations on the tensile stiffness and strength of fiber networks. Int J Solids Struct 154:19

Boufi S, González I, Delgado-Aguilar M, Tarrès Q, Pèlach M, Mutjé P (2016) Nanofibrillated cellulose as an additive in papermaking process: a review. Carbohydr Polym 154:151-166

Brandberg A, Kulachenko A (2017) The effect of geometry changes on the mechanical stiffness of fiber/fiber bonds. In: Batchelor W, Söderberg D (eds) Fundamentals of papermaking fibres, advances in paper science and technology. 
The Pulp and Paper Fundamental Research Society, Lancashire, pp 683-719

Brecht W, Klemm K (1953) The mixture of structures in a mechanical pulp as a key to knowledge of its technological properties. Pulp Paper Mag Can 54:72

Brodin FW, Eriksen Ø (2014) Preparation of individualised lignocellulose microfibrils based on thermomechanical pulp and their effect on paper properties. Nord Pulp Pap Res J 30(3):443-451

Buchanan JG, Lindsay RA (1957) A note on structure of paper as revealed by the scanning electron microscope. In: Fundamentals of papermaking fibres', transactions of the 1st fundamental research symposium held at Cambridge: September 1957. Mechanical Engineering Publications Limited, pp 101-108

Clark JD (1969) Fibrillation, free water, and fiber bonding. Tappi J 52(2):335-340

Cottrall LG (1950) The influence of hemicelluloses in woodpulp fibres on their papermaking properties. Pulp Pap Mag Can 51(9):135-143

Dasgupta S (1994) Mechanism of paper tensile-strength development due to pulp beating. Tappi J 77(6):158-166

Forgacs OL (1963) The characterization of mechanical pulp. Pulp Pap Mag Can 64(C):T89-T118

Gallay W (1949) Some factors in the strength of paper. Tappi J 32(10):457-462

Gallay W (1957) Some aspects of the theory of the beating process. In: Fundamentals of papermaking fibres, transactions of the 1st fundamental research symposium held at Cambridge: September 1957. Mechanical Engineering Publications Limited, pp 377-387

Genco JM (1999) Fundamental processes in stock preparation and refining. In: Tappi pulping conference, pp. 57-96

Gharehkhani S, Sadeghinezhad E, Kazi SN, Yarmand H, Badarudin A, Safaei MR, Zubir MNM (2015) Basic effects of pulp refining on fiber properties: a review. Carbohydr Polym 115:785-803

Giertz HW (1957) The effects of beating on individual fibres. In: Fundamentals of papermaking fibres, transactions of the 1st fundamental research symposium held at Cambridge: September 1957. Mechanical Engineering Publications Limited, pp 389-409

Hartman RR (1985) Mechanical treatment of pulp fibers for paper property development. In: Papermaking raw materials, vol 1 of transactions of the 8th fundamental research symposium held at Oxford: September 1985. Mechanical Engineering Publications Limited, pp 413-422

Ibrahimbegović A (1995) On finite element implementation of geometrically nonlinear reissner's beam theory: three-dimensional curved beam elements. Comput Methods Appl Mech Eng 122(1-2):11-26

Ingmanson W, Thode E (1959) Factors contributing to the strength of a sheet of paper II. Relative bonded area. Tappi J 42(1):83-93

ISO 10376:2011 (n.d.) Pulps: determination of mass fraction of fines

ISO 5267-1:1999 (n.d.) Pulps: determination of drainabilityPart 1: Schopper-Riegler method

ISO 5267-2:2001 (n.d.) Pulps: determination of drainabilityPart 2: "Canadian Standard" freeness method
Jayme G, Hunger G (1957) Electron microscope 2- and 3-dimensional classification of fibre bonding. In: Fundamentals of papermaking fibres, transactions of the 1st fundamental research symposium held at Cambridge: September 1957. Mechanical Engineering Publications Limited, pp 135-170

Johnson DA, Paradis MA, Bilodeau M, Crossley B, Foulger M, Gelinas P (2016) Effects of cellulosic nanofibrils on papermaking properties of fine papers. Tappi J 15(6):395-402

Joutsimo O, Robertsé L (2004) The effect of mechanical treatment on softwood kraft pulp fibers. Pulp and fiber properties. Pap Timber 86(5):359-364

Kang T (2007) Role of external fibrillation in pulp and paper properties. Helsinki University of Technology, Laboratory of Paper and Printing Technology, Espoo

Kerekes R (2005) Characterizing refining action in pfi mills. Tappi J 4(3):9-14

Kibblewhite RP (1972) Effects of beaters and wood quality on the surface and internal structure of radiata pine kraft pulp fibres. Paperi ja Puu 54(11):709-714

Kibblewhite RP (1975) Interrelations between pulp refining treatments, fibre and fines quality, and pulp freeness. Paperi ja Puu 57(8):519-526

Kim C, Page D, El-Hosseiny F, Lancaster A (1975) The mechanical properties of single wood pulp fibers. iii. The effect of drying stress on strength. J Appl Polym Sci 19(6):1549-1562

Kulachenko A, Uesaka T (2012) Direct simulations of fiber network deformation and failure. Mech Mater 51:1-14

Lammi T, Heikkurinen A (1997) Changes in fibre wall structure during defibration. In: Fundamentals of papermaking materials, vol 1 of transactions of the 11th fundamental research symposium held at Cambridge: September 1997. Mechanical Engineering Publications Limited, pp 641-662

Lavrykov S, Ramarao B, Lindström S, Singh K (2012) 3d Network simulations of paper structure. Nord Pulp Pap Res J 27(2):256-263

Lavrykov S, Singh K, Ramarao B (2011) Elasticity and stiffness of paper: a model based study of the influence of fibers. In: Proceedings of progress in paper physics seminar, pp 35-41

Lehtonen LK (2004) Elucidating the nature of bonding in mechanical pulps, $\mathrm{PhD}$ Thesis, Georgia Institute of Technology

Lobben TH (1978) On the influence of the pulp components on the shrinkage and elongation of paper. Norsk Skogind $32: 80$

Luukko K (1998) On the characterization of mechanical pulp fines. Pap Timber 80(6):441-448

Luukko K, Paulapuro H (1999) Mechanical pulp fines: effect of particle size and shape. Tappi J 82(2):95-101

Motamedian HR (2016) Robust formulations for beam-to-beam contact. Licentiate Thesis, KTH Royal institute of Technology, Stockholm, Sweden

Motamedian HR (2018) Beam-to-beam contact and its application to micromechanical simulation of fiber networks. PhD Thesis, KTH Royal institute of Technology, Stockholm, Sweden

Motamedian HR, Kulachenko A (2018) Rotational constraint between beams in 3-d space. Mech Sci 9(2):373-387 
Motamedian HR, Kulachenko A (2019) Simulating the hygroexpansion of paper using a $3 \mathrm{~d}$ beam network model and concurrent multiscale approach. Int J Solids Struct 161:23-41

Nanko H, Ohsawa J (1989) Mechanisms of fibre bond formation. In: Fundamentals of papermaking, vol 2 of transactions of the ninth fundamental research symposium held at Cambridge: September 1989. Mechanical Engineering Publications Limited, pp 783-830

Niskanen K (2008) Papermaking science and technology: paper physics. In K Niskanen (eds) Paperi ja Puu

Niskanen KJ, Alava MJ (1994) Planar random networks with flexible fibers. Phys Rev Lett 73(25):3475

Nordström B (2016) Densification by wet pressing versus refining of never-dried high-yield softwood kraft pulp: effects on compression strength, tensile stiffness, and tensile strength. Nord Pulp Pap Res J 31(3):422-431

Paavilainen L (1990) Importance of particle size-fibre length and fines-for the characterization of softwood kraft pulp. Paperi ja Puu 72(5):516-526

Page DH (1989) The beating of chemical pulps-the action and the effects. In: Fundamentals of papermaking, vol 1 of transactions of the ninth fundamental research symposium held at Cambridge: September 1989. Mechanical Engineering Publications Limited, pp 1-38

Page DH, Sargent JW (1957) The fine structure of fibre bonding. In: Fundamentals of papermaking fibres, transactions of the 1st fundamental research symposium held at Cambridge: September 1957. Mechanical Engineering Publications Limited, pp 195-200

Retulainen E, Moss P, Nieminen K (1993) Effect of fines on the properties of fibre networks. In: Products of papermaking, vol 2 of transactions of the 10th fundamental research symposium held at Oxford: September 1993. Mechanical Engineering Publications Limited, pp 727-769

Retulainen E, Nieminen K (1996) Fibre properties as control variables in papermaking: Part 2. strengthening interfibre bonds and reducing grammage. Paperi ja puu 78(5):305-312

Robertsén L, Joutsimo O (2004) The effect of mechanical treatment on kraft pulps produced from different softwood raw materials. Pulp and fiber properties. Pap Timber $87: 111$
Rusu M, Mörseburg K, Gregersen Ø, Yamakawa A, Liukkonen S (2011) Relation between fibre flexibility and crosssectional properties. Bioresources 6(1):641-655

Scallan AM (1983) The effect of acidic groups on the swelling of pulps: a review. Tappi J 66(11):73-75

Sehaqui H, Zhou Q, Berglund LA (2013) Nanofibrillated cellulose for enhancement of strength in high-density paper structures. Nord Pulp Pap Res J 28(2):182

Seth RS (2003) The measurement and significance of fines. Pulp Pap Can 104(2):41-44

Stoere P, Nazhad M, Kerekes R (2001) An experimental study of the effect of refining on paper formation. Tappi $\mathrm{J}$ 84(7):201-208

Strachan J (1932) Further notes on the hydration of cellulose in papermaking. In: Proceedings of the technical section. Mechanical Engineering Publications Limited, pp. $61-81$

Sundberg A, Holmbom B (2004) Fines in spruce tmp, btmp and ctmp-chemical composition and sorption of mannans. Nord Pulp Pap Res J 19(2):176-182

Sundberg A, Pranovich AV, Holmbom B (2003) Chemical characterization of various types of mechanical pulp fines. J Pulp Pap Sci 29(5):173-178

TAPPI T 227 om-99 (n.d.) Freeness of pulp (Canadian standard method)

TAPPI T $261 \mathrm{~cm}-94$ (n.d.) Fines fraction of paper stock by wet screening

Tasman JE (1969) Control, secondary fiber, structural board, coating, pulp and paper manufacture: joint textbook committee of the paper industry. McGraw-Hill Book Company, New York

Vainio A, Paulapuro H (2007) Interfiber bonding and fiber segment activation in paper. Bioresources 2(3):442-458

Wernersson ELG, Borodulina S, Kulachenko A, Borgefors G (2014) Characterisations of fibre networks in paper using micro computed tomography images. Nord Pulp Pap Res J 29(3):468-475

Publisher's Note Springer Nature remains neutral with regard to jurisdictional claims in published maps and institutional affiliations 